\title{
Membrane Potential Correlates of Network Decorrelation and Improved SNR by Cholinergic Activation in the Somatosensory Cortex
}

\author{
Inbal Meir, ${ }^{\star}$ Yonatan Katz, ${ }^{*}$ and $\odot$ Ilan Lampl \\ Department of Neurobiology, Weizmann Institute of Science, Rehovot 7610001, Israel
}

The nucleus basalis (NB) projects cholinergic axons to the cortex, where they play a major role in arousal, attention, and learning. Cholinergic inputs shift cortical dynamics from synchronous to asynchronous and improve the signal-to-noise ratio (SNR) of sensory responses. However, the underlying mechanisms of these changes remain unclear. Using simultaneous extracellular and whole-cell patch recordings in layer 4 of the mouse barrel cortex, we show that electrical or optogenetic activation of the cholinergic system has a differential effect on ongoing and sensory evoked activities. Cholinergic activation profoundly reduced the large spontaneous fluctuations in membrane potential and decorrelated ongoing activity. However, NB stimulation had no effect on the response to whisker stimulation or on signal correlations. These effects of cholinergic activation provide a unified explanation for the increased SNR of sensory response and for the reduction in noise correlations and explain the shift into the desynchronized cortical state, which are the hallmarks of arousal and attention.

Key words: barrel cortex; cholinergic; decorrelation; in-vivo intracellular recordings; nucleus basalis; SNR

\section{Significance Statement}

Attention increases the signal-to-noise ratio (SNR) of cortical sensory response, which may reflect either reduction in background firing rate or increased sensory response. Extracellular recordings showed that attention also reduces the correlation in network activity. These effects are partially mediated by cholinergic axons from the nucleus basalis projecting to the entire cortex. To reveal the cellular and synaptic correlates of these cholinergic effects, we performed simultaneous intracellular and LFP recordings in the somatosensory cortex. Global or local cholinergic activation increased the SNR of sensory response mainly by reducing the rate and amplitude of background synaptic activity and also reduced network correlations. Therefore, coding of sensory information is enhanced by the cholinergic system mainly due to a reduction in spontaneous activity.

\section{Introduction}

The nucleus basalis (NB) plays a major role in arousal, attention, learning, and plasticity (Kilgard and Merzenich, 1998; Herrero et al., 2008; Froemke et al., 2013; Chubykin et al., 2013; Xu et al.,

Received May 7, 2018; revised 0ct. 8, 2018; accepted 0ct. 10, 2018.

Author contributions: I.M. and I.L. wrote the first draft of the paper; I.M., Y.K., and I.L. edited the paper; I.M.,Y.K., and I.L. designed research; I.M. and Y.K. performed research; I.M., Y.K., and I.L. analyzed data; I.M., Y.K., and I.L. wrote the paper.

The authors declare no competing financial interests.

This research was supported by DFG (SFB 1089), EraNet (DeCipher Neuron 01EW1606), Human Frontier Science Program Grant, Israel Science Foundation (ISF 1539/17), Minerva, and the Marianne Manoville Beck Laboratory for Research in Neurobiology in Honor of her Parents Elisabeth and Miksa Manoville, all awarded to I.L. Y.K. is the Marianne Manoville Beck Research Fellow Chair in Brain Research. We thank all members of the Lampl laboratory and Katayun Cohen-Kashi-Malina and Matthias Prigge for helpful contributions to this work.

*I.M. and Y.K. contributed equally to this work.

Correspondence should be addressed to llan Lampl, Department of Neurobiology, Weizmann Institute of Science, 234 Herzl St., Rehovot 7610001, Israel. E-mail: Ilan.Lampl@weizmann.ac.il.

https://doi.org/10.1523/JNEUROSCl.1159-18.2018

Copyright $\odot 2018$ the authors $\quad 0270-6474 / 18 / 3810692-17 \$ 15.00 / 0$
2015). NB neurons send mostly cholinergic, but also GABAergic and glutamatergic, projections to the cortex (Gritti et al., 1997; Henny and Jones, 2008; Do et al., 2016). During active states such as locomotion or whisking, cholinergic axons become active (Eggermann et al., 2014; Reimer et al., 2016). In vivo NB activation or cholinergic modulation shift cortical dynamics from synchronous to asynchronous state, as seen in cortical EEG (Metherate et al., 1992; Kalmbach et al., 2012) and improves cue detection and visual discrimination (Parikh et al., 2007; Herrero et al., 2008; Goard and Dan, 2009; Gritton et al., 2016), whereas lesioning the NB impairs attention performance (Risbrough et al., 2002; Ljubojevic et al., 2014).

Acetylcholine enhances the cortical sensory response by facilitating the thalamocortical inputs in L4 while suppressing the corticocortical inputs, thereby improving the signal-to-noise ratio (SNR) (Gil et al., 1997; Oldford and Castro-Alamancos, 2003; Disney et al., 2007, 2012; Soma et al., 2013). In two recent studies (Pinto et al., 2013; Minces et al., 2017), local optogenetic activa- 
tion of cholinergic axons in V1 led to increased SNR due to increased signal amplitude with no change in the noise amplitude. In contrast, other studies reported a cholinergic suppression of the sensory evoked spike response of L4 cells in the somatosensory and auditory cortex in vivo (Sillito and Kemp, 1983; Donoghue and Carroll, 1987), suppression of both thalamocortical and intracortical synapses in L4 in the auditory cortex (A1) (Hsieh et al., 2000), and a persistent hyperpolarization of L4 cells in S1, A1, and V1 in vitro (Eggermann and Feldmeyer, 2009). Cholinergic modulation, NB activation, or attention can further improve population sensitivity by neuronal spike decorrelation and by reducing noise correlations (Cohen and Maunsell, 2009; Goard and Dan, 2009; Briggs et al., 2013; Pinto et al., 2013; Polack et al., 2013). The synaptic dynamics underlying the increase of sensory SNR and the desynchronization of the LFP and neuronal firing remain unclear.

Using whole-cell patch recordings and simultaneous LFP in awake and anesthetized animals, we studied how global NB activation or local optogenetic activation of cholinergic fibers affect cortical layer 4 ongoing and evoked activities in the barrel cortex. We found that both types of stimulation had very similar effects on the cortical activity in L4. They suppressed the spontaneous activity and correlations of ongoing activity, but had no effect on the response to whisker stimulation. Therefore, cholinergic activation led to a higher SNR of the sensory response and to a lower noise correlation in the local network.

\section{Materials and Methods}

\section{Animals}

All surgical and experimental procedures were performed in accordance with the regulations of The Weizmann Institute Animal Care and Use Committee. Recordings were made on young adult mice of either sex (9-16 weeks old) housed up to 5 in a cage with a $12 / 12 \mathrm{~h}$ dark/light cycle. In experiments involving optogenetic cholinergic activation, we used ChAT-ChR2(Ai32) mice, which were the product of crossing lines B6;129S6-Chat ${ }^{\mathrm{tm} 1 \text { (cre)Lowl } / J ~(C h A T-C r e ; ~ J a x ~ 006410) ~}$

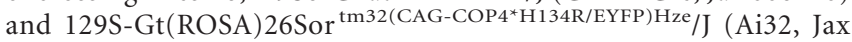
012569) (Madisen et al., 2012). ChAT-Cre ${ }^{+}$mice were crossed with $\mathrm{ChR}^{+1+}$ mice to yield $\mathrm{Cre}^{+} \mathrm{ChR} 2^{+/-}$offspring. These offspring were crossed to generate $\mathrm{Cre}{ }^{+} \mathrm{ChR} 2{ }^{+/+}$mice, which were used for experiments. In NB stimulation experiments, we used C57BL/6J mice.

\section{Anesthetized animal preparation}

Mice (15-30 g) were initially anesthetized intraperitoneally with ketamine $(100 \mathrm{mg} / \mathrm{kg})$ and xylazine $(5 \mathrm{mg} / \mathrm{kg})$. After the initial induction of anesthesia, animals were tracheotomized following the application of a local anesthetic, lidocaine (1\%), injected subcutaneously and then a small metal tube was inserted into the trachea. Anesthesia was maintained by means of halothane $(0.5-1 \%)$ and body temperature was kept at $37^{\circ} \mathrm{C}$ using a heating blanket. Craniotomy was performed over the somatosensory cortex ("barrel cortex" centered $1.3 \mathrm{~mm}$ posterior and $3.3 \mathrm{~mm}$ lateral from bregma). In NB activation experiments, another craniotomy was made over the NB (1 mm posterior and 1.7 $\mathrm{mm}$ lateral from bregma).

\section{Awake animal preparation}

Animals underwent the implantation of a head bar to allow awake, headfixed recordings as follows: following initial anesthesia in an induction chamber containing a mixture of isoflurane and oxygen-enriched air, the animals were mounted in a stereotaxic device and kept deeply anesthetized with isoflurane $1-1.5 \%$ while being monitored for lack of reflexes and breathing rate. The area of incision was treated with lidocaine and cleaned with iodine and $70 \%$ ethanol. The skullcap was exposed and cleaned. A customized plastic head-bar was firmly affixed to the skull with dental acrylic $(3 \mathrm{M})$ and the skull above the barrel cortex (centered $1.3 \mathrm{~mm}$ posterior and $3.3 \mathrm{~mm}$ lateral from the bregma) was covered with silicone rubber (Smooth-On). Thirty minutes before the end of the sur- gery, the animals were injected subcutaneously with buprenorphine $(0.1$ $\mathrm{mg} / \mathrm{kg})$ and carpofen $(5 \mathrm{mg} / \mathrm{kg})$.

Following a recovery period ( $4-7 \mathrm{~d})$, the animals were anesthetized in an induction chamber containing a mixture of isoflurane and oxygenenriched air. The animals were then mounted in a stereotaxic device and kept anesthetized. The silicon rubber covering the skull over the barrel cortex was removed and a craniotomy was performed exposing the barrel cortex and leaving the dura intact. The brain was then covered in an agar layer $(2 \% \mathrm{w} / \mathrm{v})$ held in place with silicone rubber and the animal was returned to the cage for a recovery period of $2 \mathrm{~h}$. The animal was then returned to the set and head-fixed for the electrophysiological recordings.

\section{Electrophysiology}

$L F P$ recordings. For LFP recordings, patch micropipettes were filled with artificial CSF (ACSF) containing the following (in $\mathrm{mm}$ ): $124 \mathrm{NaCl}, 26$ $\mathrm{NaHCO} 3,10$ glucose, $3 \mathrm{KCl}, 1.24 \mathrm{KH}_{2} \mathrm{PO}_{4}, 1.3 \mathrm{MgSO}_{4}$, and $2.4 \mathrm{CaCl}_{2}$. The pipette was inserted to a depth of $400-450 \mu \mathrm{m}$ from pia. The signal was band-pass filtered at $1-160 \mathrm{~Hz}$ before being digitized at $10 \mathrm{kHz}$. LFP was referenced to a chlorinated silver wire that was inserted under the skin of the neck. In simultaneous recordings of membrane potential and LFP $\left(V_{\mathrm{m}}-\mathrm{LFP}\right)$, the LFP pipette tip was placed at horizontal distance $<500 \mu \mathrm{m}$ from the recorded cell.

Extracellular recordings. Extracellular recordings were performed using patch micropipettes filled with patch solution. Recordings in cellattached mode were made in the barrel cortex with a regular pipette holder and in the NB using an optopatcher (Katz et al., 2013) (A-M Systems). The signals were amplified using a MultiClamp 700B amplifier (Molecular Devices), band-pass filtered at $0.3-3 \mathrm{kHz}$, and digitized at $10 \mathrm{kHz}$.

Whole-cell patch recordings. Borosilicate micropipettes were pulled to produce electrodes with a resistance of 4-10 $\mathrm{M} \Omega$ when filled with an intracellular solution containing the following (in mM): $136 \mathrm{~K}$-gluconate, $10 \mathrm{KCl}, 5 \mathrm{NaCl}, 10$ HEPES, $1 \mathrm{MgATP}, 0.3 \mathrm{NaGTP}$, and 10 phosphocreatine, mOsm 310. In some of the recordings, QX-314 (2 mM) was added to prevent spikes. Recording depth ranged between 300 and $500 \mu \mathrm{m}$ below pia. Intracellular signals were acquired using a MultiClamp 700B amplifier and low-pass filtered at $3 \mathrm{kHz}$ before being digitized at $10 \mathrm{kHz}$.

\section{Pharmacology}

We used the acetylcholine receptor (AChR) antagonists atropine $(0.5$ mM; A0132, Sigma-Aldrich) and mecamylamine (1 mm; M9020, SigmaAldrich) in ACSF to determine whether the effect of NB stimulation on cortical LFP is mediated by local AChRs. The mixture was applied topically and recording tests started at least $45 \mathrm{~min}$ after the application of the blockers.

\section{Histology and immunohistochemistry}

At the end of the experiment, the animals were overdosed with anesthesia and transcardially perfused with PBS followed by cold $2.5 \% \mathrm{w} / \mathrm{v}$ paraformaldehyde (PFA). The brain was removed and postfixed in PFA for $24 \mathrm{~h}$, followed by cryoprotection with $30 \%(\mathrm{w} / \mathrm{v})$ sucrose in PBS solution. The brain was then sectioned in $30-\mu \mathrm{m}$-thick coronal slices using a sliding microtome (Leica SM 2010R). The slices were mounted with ImmuMount (Thermo Scientific). In experiments in which the NB was electrically stimulated, the slices were examined and images of NB lesions were acquired with a fluorescent stereomicroscope (Leica M165 FC). To confirm specific expression of ChR2 in cholinergic neurons, we performed ChAT immunohistochemistry. Brain slices were thoroughly washed with PBS and incubated for $1 \mathrm{~h}$ with blocking buffer $(20 \% \mathrm{w} / \mathrm{v}$ normal horse serum, $0.2 \% \mathrm{v} / \mathrm{v}$ Triton X-100 in PBS). The buffer was washed out with PBS and the slices were then incubated overnight at $4^{\circ} \mathrm{C}$ with primary antibody (1:100 dilution, goat anti-ChAT IgG (catalog \#AB144P, Millipore) and mouse anti-GFP IgG (catalog \#MAB3580, Millipore), washed, and incubated for $1.5 \mathrm{~h}$ at room temperature with the secondary antibody (1:200 dilution, biotinylated donkey anti-goat IgG (catalog \#705065-147 JAC, Jackson Laboratories), or Cy2-conjugated anti-mouse (catalog \#715-225-151 JAC, Jackson Laboratories). Images were acquired with a confocal microscope (Zeiss, LSA 880) and processed in Adobe Photoshop 7.0. 


\section{Sensory stimulation}

Whiskers were trimmed to a length of $10-15 \mathrm{~mm}$. The principal whisker was inserted into a $21 \mathrm{G}$ needle and mechanically stimulated by a train of 10 deflections (20 ms duration) precisely controlled by a galvanometer servo control motor $(6210 \mathrm{H}$; Cambridge Technology) used with a matching servo driver and a controller (MicroMax 677xx; Cambridge Technology) at 10 or $20 \mathrm{~Hz}$. In the majority of experiments, we introduced an additional "recovery" stimulus, a single whisker deflection that was delivered $500 \mathrm{~ms}$ past train offset. The displacement was measured offline using an optical displacement measuring system (optoNCDT 1605, Micro-Epsilon), indicating that ringing was negligible. A fast-rising voltage command was used to evoke a fast whisker deflection with a constant rise time of $\sim 1 \mathrm{~ms}$ followed by a $20 \mathrm{~ms}$ ramp-down signal. The stimulation velocity and the corresponding deflection amplitude $(\sim 50$ $\mathrm{mm} \mathrm{s}^{-1}, 145 \mu \mathrm{m}$ amplitude) were adjusted to evoke clear subthreshold responses in the cortical cells.

In experiments with awake, head-fixed mice, whisker movements were monitored using a reflective sensor (HOA1405) mounted on articulated arm. The sensor was positioned $0.5 \mathrm{~cm}$ from the animal's head and enabled the detection of whisking epochs and their phase.

\section{Electrical stimulation of the NB}

We stereotaxically placed a concentric needle electrode (30 G; Alpine Biomed) in the NB in the area that modulates the somatosensory cortex ( $1 \mathrm{~mm}$ posterior and $1.7 \mathrm{~mm}$ lateral and $4.5-5 \mathrm{~mm}$ ventral from bregma). A train of 50 current pulses of $100-200 \mu \mathrm{A}$ at $100 \mathrm{~Hz}$, pulse duration 0.5 $\mathrm{ms}$, was injected by an isolation unit (ISO-Flex; A.M.P.I. Instruments). The depth positioning of the bipolar electrode was adjusted at the beginning of each experiment based on the cortical LFP responses to the electrical stimulation (ES). Once the stimulating electrode position was set, it remained the same throughout the experiment. The stimulating electrode location was marked for histology at the end of the experiment by a current-induced lesion $(2 \mathrm{~s}, 5 \mathrm{~mA} \times 5$ times). Due to stimulation artifacts, we were unable to analyze the modulation of LFP during the 500 $\mathrm{ms}$ of NB electrical stimulation (masked by a gray bar in Fig. 1C).

\section{Optogenetic stimulation}

For optogenetic stimulation, we used an analog modulated blue DPSS laser $(\lambda=473 \mathrm{~nm}$, Shanghai Dream Lasers Technology) coupled to a multimode fiber (numerical aperture $=0.22,200 \mu \mathrm{m}$ core). The intensity of the light was $\sim 7 \mathrm{~mW}$ at the tip of the fiber. For local cortical stimulation, a continuous light pulse 3 or $4 \mathrm{~s}$ long was given through a fiber that was placed $<1 \mathrm{~mm}$ above the surface of the brain. In recordings from the NB, an optopatcher (Katz et al., 2013) was inserted into the NB in the area that modulates the somatosensory cortex ( $1 \mathrm{~mm}$ posterior and $1.7 \mathrm{~mm}$ lateral and $4.5-5 \mathrm{~mm}$ ventral from bregma). Light pulses of $10 \mathrm{~ms}$ at frequencies between 1 and $15 \mathrm{~Hz}$ were delivered in the NB.

\section{Experimental design}

Stimulation protocol was composed of three trials in each repetition: (1) $\mathrm{NB}$ /optogenetic stimulation alone, (2) whisker stimulation alone, or (3) $\mathrm{NB} /$ light + whisker stimulation. Due to the long-lasting effect of NB stimulation, we recorded 10-s-long trials with intertrial intervals of $10 \mathrm{~s}$, allowing the neuronal activity to return to baseline. Trials were pseudorandomized. Each trial type was repeated at least eight times in each cell. In the majority of experiments, we noticed a "bump" of activity immediately following NB stimulation offset, manifested as a bump with negative polarity in the LFP, increased spontaneous spiking in cell-attached recordings, and large spontaneous $V_{\mathrm{m}}$ depolarizations in whole-cell recordings, which could last from 0.1 to $1 \mathrm{~s}$. We were interested in the prolonged effects of NB stimulation and therefore we set the onset of sensory stimulation to $1.5-2 \mathrm{~s}$ following NB stimulation offset, after the $V_{\mathrm{m}}$ has stabilized. The analysis of spontaneous activity described next was performed on time windows of $2 \mathrm{~s}$ starting $2.6 \mathrm{~s}$ before NB stimulation onset and $2.1 \mathrm{~s}$ after NB stimulation offset. Although the time window was fixed, changing the starting time and the duration of the window by up to several hundred milliseconds had negligible effects on the results that were obtained using the analysis methods described below.

\section{Data analysis}

The data were analyzed using custom software written in MATLAB (The MathWorks).

\section{Spectral analysis of LFP}

For spectral analysis of LFP, we took the mean-subtracted traces from trials in which no sensory stimulation was introduced. We chose a 2-slong window starting $2.1 \mathrm{~s}$ past the offset of $\mathrm{NB}$ stimulation and a window of the same duration starting $2.6 \mathrm{~s}$ before NB stimulation onset. The power spectral density is the square of the fast Fourier transform over a frequency range between 1 and $49 \mathrm{~Hz}$.

\section{Analysis of extracellular spikes}

In cell-attached recordings, raster plots were binned at $10 \mathrm{~ms}$ bins to produce peristimulus time histograms (PSTHs). Response magnitude was calculated from the PSTHs as follows:

$$
\text { Response magnitude }=F R_{\text {stim }}-F R_{b g}
$$

where $F R_{\text {stim }}$ is the average firing rate during $500 \mathrm{~ms}$ of sensory train stimulus and $F R_{b g}$ is the background averaged firing rate during $500 \mathrm{~ms}$ immediately before the sensory stimulus. By subtracting the rate of background spikes from that during stimulation, we estimated the net response to sensory stimulation, which we refer to as the signal.

To quantify the SNR, as evaluated from the response and background firing, we calculated an SNR index, which ranges between -1 and 1 (Vinck et al., 2015), as follows:

$$
S N R \text { index }=\frac{F R_{S t i m}-F R_{b g}}{F R_{S t i m}+F R_{b g}}
$$

Where $F R_{\text {stim }}$ and $F R_{b g}$ are the same parameters as used when calculating the response magnitude [both for $\mathrm{NB}(+)$ and $\mathrm{NB}(-)$ ].

\section{Analysis of $V_{m}$}

In whole-cell recordings, some of the cells were spiking and the spikes were removed offline by spline interpolation based on five samples on each side of the action potential (Okun and Lampl, 2008).

For calculation of $V_{\mathrm{m}} \mathrm{SNR}$, we used a definition of SNR of a waveform signal as the ratio of signal power and noise power. When we were interested in the amplitude around the mean of the waveform and not relative to zero, such as our case, the SNR is equivalent to the ratio of signal variance and noise variance (Smith, 1997) as follows:

$$
\text { SNR }=\frac{\text { Power }_{\text {signal }}}{\text { Power }_{\text {noise }}}=\frac{\text { Amplitude }}{\text { signal }}=\frac{\sigma_{\text {signal }}^{2}}{\text { Amplitude }_{\text {noise }}^{2}}
$$

We took the signal to be the mean over trials of the sensory-evoked response and the noise as the residuals; that is, the fluctuations around the mean. Therefore, we calculated the amplitude of the signal and the noise. The amplitude of a waveform is given by the following:

$$
\text { Amplitude }_{\text {waveform }}=\sqrt{\frac{1}{T} \sum_{t=1}^{T}(x(t)-\bar{x})^{2}}=\sigma
$$

Where $\bar{x}$ is the mean voltage over time, $x(t)$ is the voltage at each time point $t$, and $T$ is the total number of samples in the trace. For the noise amplitude, we calculated the amplitude waveform of each residual trace and then averaged these values over trials. Finally, we squared both signal amplitude and noise amplitude. The ratio between them is the SNR.

Whisk power was calculated in a similar way to signal power, as the variance of single whisk trials averaged over trials.

To quantify the effect of NB stimulation or optogenetic stimulation on the mean and trial-to-trial variability of the $V_{\mathrm{m}}$, we calculated the spontaneous and sensory-evoked $V_{\mathrm{m}}$ mean and standard deviation (SD). For each time point, the mean or SD was calculated for all the trials and then these values were averaged to obtain a single value. The following time windows were used for the calculation: (1) spontaneous $V_{\mathrm{m}}$ mean and SD were calculated from trials in which no sensory stimulus was presented in time windows $2 \mathrm{~s}$ long starting $2.6 \mathrm{~s}$ before NB stimulation or light onset 
and $2.1 \mathrm{~s}$ after NB stimulation and $1 \mathrm{~s}$ after light onset, and (2) sensoryevoked $V_{\mathrm{m}}$ mean and SD were calculated from 50-ms-long time windows following each stimulus in the train, and then averaged over the stimuli in the train. The calculated values were compared between the two conditions with and without NB stimulation or optogenetic stimulation.

\section{Analysis of spontaneous postsynaptic potentials (PSPs)}

The amplitude of spontaneous PSPs was measured as the difference between PSP peak and PSP onset values (Ankri et al., 1994; Kudoh and Taguchi, 2002; Okun and Lampl, 2008). Briefly, after smoothing the data, onset and peak values were detected using the voltage derivative. Events with an amplitude that was $>1.5 \mathrm{mV}$ were considered PSPs rather than noise. This amplitude is somewhat above the $\sim 1 \mathrm{mV}$ amplitude of noise fluctuations in the $V_{\mathrm{m}}$ recordings observed in raw data traces at the resting potential. We manually verified correct detection of events to ensure optimal detection, with emphasis on minimizing false positives while slightly compromising false negatives (i.e., missed events). Examples for spontaneous events detected are shown in Figure $6 \mathrm{~A}$.

Histograms of PSP amplitude were made with $0.5 \mathrm{mV}$ bins. The confidence interval for the median PSP amplitude was computed using the bootstrap method. We resampled the data (with returns) and generated 5000 datasets. We calculated the median of each dataset and, from these values, took the 2.5 percentile and the 97.5 percentile to be the $95 \%$ confidence interval of the median.

Analysis of whisker-evoked responses during repetitive stimulation Whisker-evoked responses to individual deflections during train stimulation were analyzed to quantify the degree of adaptation. This was done by calculating the adaptation-amplitude ratio (AAR) after averaging the $V_{\mathrm{m}}$ across all trials during train of whisker stimuli (10 stimuli, $10 \mathrm{~Hz}$, starting 1.0-1.5 s after termination of the NB stimulation or onset of optogenetic stimulation; see above). AAR was obtained by calculating the ratio between the mean response amplitude of the last three stimuli in the train to the response amplitude of the first stimulus. Amplitudes were normalized by the averaged response to the first stimulus during the control condition (i.e., in absence of NB or optogenetic stimulation). The amplitude of the average response for each stimulus was measured from the difference between peak response in the first $30 \mathrm{~ms}$ and the mean $V_{\mathrm{m}}$ in the first $3 \mathrm{~ms}$ after whisker deflection.

Cross-correlation between $\mathrm{V}_{\mathrm{m}}$ and LFP

Three types of $V_{\mathrm{m}}$-LFP correlations were obtained from the paired recordings: (1) raw cross-correlations, (2) noise correlations, and (3) signal correlations.

For the cross-correlations of the spontaneous activity during control condition, we analyzed an epoch of $2 \mathrm{~s}$ duration starting $2.6 \mathrm{~s}$ before NB stimulation or optogenetic stimulation onset. The effect of cholinergic activation on the cross-correlation of these two signals was determined on an epoch of $2 \mathrm{~s}$ starting $2.1 \mathrm{~s}$ after the offset of NB stimulation and $1 \mathrm{~s}$ after the onset of optogenetic stimulation. For sensory-evoked activity, as all cells in this analysis were sensory stimulated at $10 \mathrm{~Hz}$; we took an interval of $1 \mathrm{~s}$ starting at the onset of the sensory stimulation train.

The raw $V_{\mathrm{m}}$-LFP cross-correlation was computed using MATLAB's 'xcorr' function (setting option to 'coeff' to obtain normalized output). The mean value of each signal for every trial was subtracted before the calculation. $V_{\mathrm{m}}$-LFP noise correlations of both ongoing and sensory evoked activities were obtained in a similar method, but the average trace of each signal (obtained from all the trials) was subtracted from each trial before calculating the cross-correlation. This subtraction removed the contribution of the average time-locked response to NB or optogenetic stimulations. The averaged raw and noise correlations obtained from all the trials are shown for different examples together with \pm SD in Figures 10 and 11 .

To determine how NB or optogenetic stimulation changes these correlations in the population of different $V_{\mathrm{m}}$-LFP paired recordings, we took for each trial the absolute value of the zero-lag cross-correlation (Pearson correlation) and averaged them over all the trials, resulting in two single values for each cell: one value for control conditions and one value following cholinergic activation. We present these values separately for ongoing and whisker-evoked activities. These measurements were made both for raw and noise correlations (see Figs. 10, 11).

Signal correlation during whisker train stimulation was calculated from the cross-correlation of the average $V_{\mathrm{m}}$ and average LFP for all the trials using the same MATLAB function.

\section{Statistical analysis}

The statistical analyses for the populations was conducted using either Wilcoxon's signed-rank test or repeated-measures two-way ANOVA (with the standard Greenhause-Geisser correction in cases where sphericity was violated), followed by Tukey's HSD post hoc tests. The significance level was at least $p<0.05$.

\section{Results}

\section{NB stimulation desynchronizes cortical LFP and increases SNR}

To determine how activation of the NB affects cortical synaptic activity, we recorded LFP in the barrel cortex at a depth of 400$450 \mu \mathrm{m}$, which corresponds to layer 4 , in lightly anesthetized mice. We electrically stimulated the ipsilateral NB (see Materials and Methods) (see Fig. $1 A$ for a schematic illustration of the method). A lesion performed at the end of the experiment verified the location of the stimulating electrode histologically. An example is shown in Figure $1 B$, illustrating a clear lesion at the corresponding location of the NB.

Previous studies have shown that NB or cholinergic activation exerts both transient and prolonged modulation of cortical activity. NB activation causes desynchronization in EEG or LFP activity manifested by elimination of slow waves and reduced spectral power in low frequencies $(1-10 \mathrm{~Hz})$, as well as an increase in gamma power $(30-80 \mathrm{~Hz})$. This effect could last several seconds (Kalmbach and Waters, 2014).

Consistent with the aforementioned studies, electrical stimulation at the corresponding depth of the NB caused an overall reduction in spectral power, especially at low frequencies (Fig. $1 C, D)$. For a population of LFP recordings from 7 experiments, we saw a significant decrease in the total power (from $9.99 \pm$ $4.37 \cdot 10^{3}$ to $5.38 \pm 2.77 \cdot 10^{3} \mathrm{mV}^{2} / \mathrm{Hz}, p=0.015$, Wilcoxon's signed-rank test, $n=7$ animals, Fig. $1 E$ ). This is a result of a general decrease in all 3 frequency bands tested: low frequency $(1-10 \mathrm{~Hz})$, beta $(12-25 \mathrm{~Hz})$, and gamma $(30-50 \mathrm{~Hz})(p=0.015$, $p=0.015$, and $p=0.031$, respectively, Wilcoxon's signed-rank test, $n=7$ experiments, Fig. $1 E$ ).

We next sought to determine whether the reduction of ongoing activity following NB stimulation was mediated by local activation of cholinergic receptors. Therefore, we used topical application of the AChR antagonists $0.5 \mathrm{~mm}$ atropine and $1 \mathrm{~mm}$ mecamylamine during LFP recordings and NB stimulation. An example of such an experiment is presented in Figure 1, F-I, demonstrating that the reduction in ongoing activity following NB stimulation was almost completely reversed when we applied these blockers, as was further confirmed in the power spectra for these two conditions (see Fig. 1G,I for the time windows that are depicted by the shaded boxes in the traces). In the presented experiment, low-frequency power (sum of power between 1 and $10 \mathrm{~Hz}$ ) was significantly reduced following NB stimulation (from $5.21 \pm 2.49 \cdot 10^{3}$ to $2.39 \pm 1.00 \cdot 10^{3} \mathrm{mV}^{2} / \mathrm{Hz}, p=0.003$, Wilcoxon's signed-rank test, $n=1$ animal, at least 15 repetitions in each condition, data not shown). After application of cholinergic blockers, NB stimulation had no effect on the low-frequency power (from $8.72 \pm 5.10 \cdot 10^{3}$ to $7.48 \pm 6.03 \cdot 10^{3} \mathrm{mV}^{2} / \mathrm{Hz}, p=$ 0.54 , Wilcoxon's signed-rank test, $n=1$ animal, at least 15 repetitions in each condition, data not shown). This observation was further supported in 3 other animals in which NB stimulation 

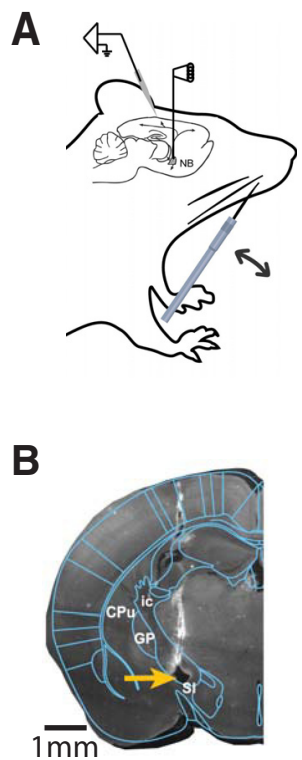

F

ACSF

ATR+MEC
C

Barrel cortex L4 LFP traces

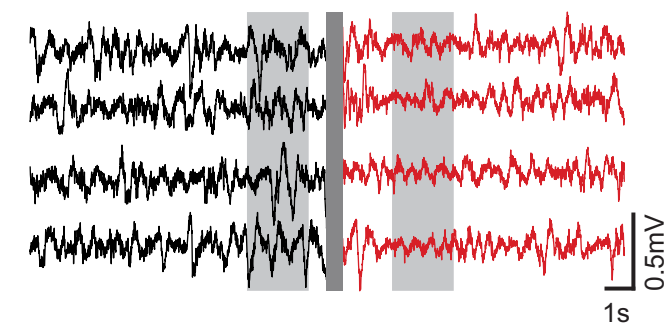

E

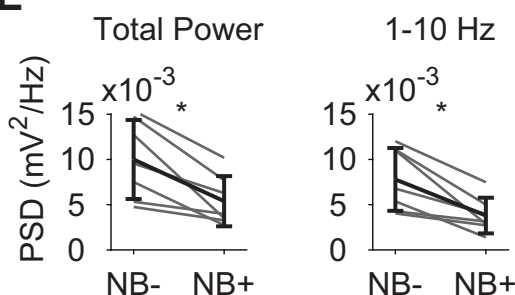

D

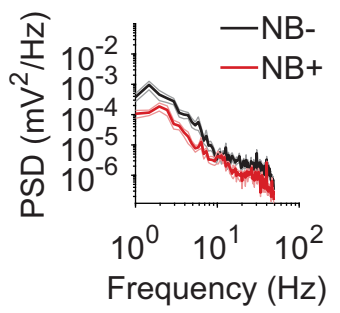

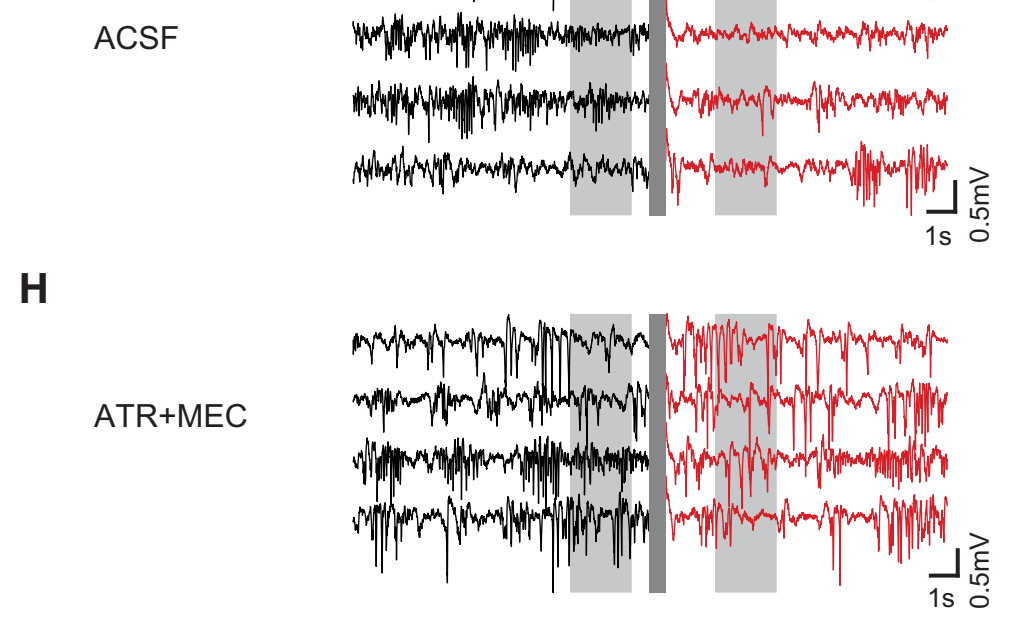

G

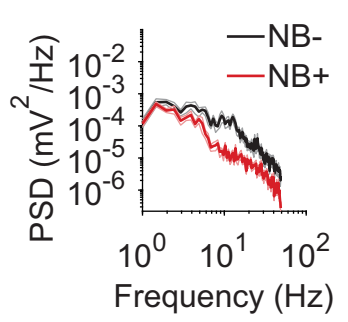

I
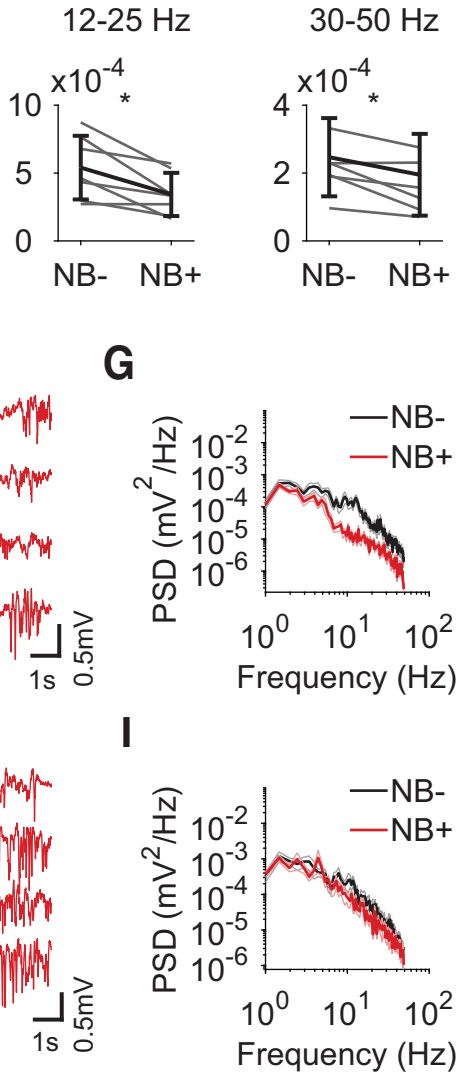

Figure 1. NB stimulation shifts the cortex into an asynchronous state. $A$, Schematic illustration of the experimental setup. Recordings in the barrel cortex were performed either with a single patch pipette or two pipettes for intracellular and nearby LFP recordings. B, A lesion (orange arrow) marks the location of electrical stimulation electrode, corresponding to NB location. GP, Globus pallidus; CPu, caudate putamen; SI, substantia innominata (which contains the NB); ic, internal capsule. C, Barrel cortex layer 4 LFP before (black; NB -) and after (red; NB +) $100 \mathrm{~Hz}$ electrical stimulation of the NB (masked by the dark gray rectangle). Light gray rectangles mark the $2 \mathrm{~s}$ windows from the traces used to calculate the PSD in $\boldsymbol{D}$ and $\boldsymbol{E}$. The trial averaged PSD is presented as mean \pm SEM. $\boldsymbol{E}$, Left to right, Total power is the sum of the $V_{\mathrm{m}}$ power spectrum, sum of power in frequencies $1-10 \mathrm{~Hz}$, sum of power in frequencies $12-25 \mathrm{~Hz}$, corresponding to beta band, sum of power in frequencies $30-50 \mathrm{~Hz}$, corresponding to lower gamma band. Wilcoxon's signed-rank test, $n=7$ experiments. $\boldsymbol{F}, \boldsymbol{H}$, Barrel cortex layer 4 LFP traces before (black; NB - ) and after (red; NB + ) electrical stimulation of the NB (similar to $\boldsymbol{C}$, with ACSF only $(\boldsymbol{F})$ and after the application of cholinergic antagonists atropine and mecamylamine $(\boldsymbol{H})$. Gray rectangles mark the $2 \mathrm{~s}$ windows from the traces used to calculate the PSD in $\mathbf{G}$ and $\boldsymbol{I}$, respectively. ${ }^{*} p<0.05$.

significantly reduced the low-frequency power $(p<0.02)$ and, following the application of the blockers, NB stimulation had no effect on this low-frequency power $(p>0.1)$. Therefore, a significant portion of the effect of NB stimulation on cortical LFP was mediated by local AChRs.

\section{NB stimulation increases the SNR of the}

sensory-evoked response

To study the effect of NB stimulation on the SNR of the sensory-evoked response, we recorded juxtacellularly the spiking response of barrel cortical neurons to repetitive whisker deflection delivered either 1.5-2 s after NB stimulation or without stimulating the NB.
A total of 11 cells were recorded juxtacellularly in 8 animals, 1-3 cells per animal: 9 cells were recorded at depth of $350-600$ $\mu \mathrm{m}$, corresponding to layer 4 and 2 cells at $850-900 \mu \mathrm{m}$, corresponding to layer 5-6. The raster plots and PSTHs of two example cells (at recording depths 356 and $410 \mu \mathrm{m}$, respectively) are presented in Figure 2, showing a suppression of background spikes following NB stimulation, whereas the magnitude of the evoked responses remained unchanged (Fig. $2 A-D$ ). All cells except one had wide spikes and could be considered putative excitatory cells (Mitchell et al., 2007). The putative inhibitory cell had similar responses.

To estimate the effect of NB stimulation on the response, we calculated the response magnitude (see Materials and Methods). 

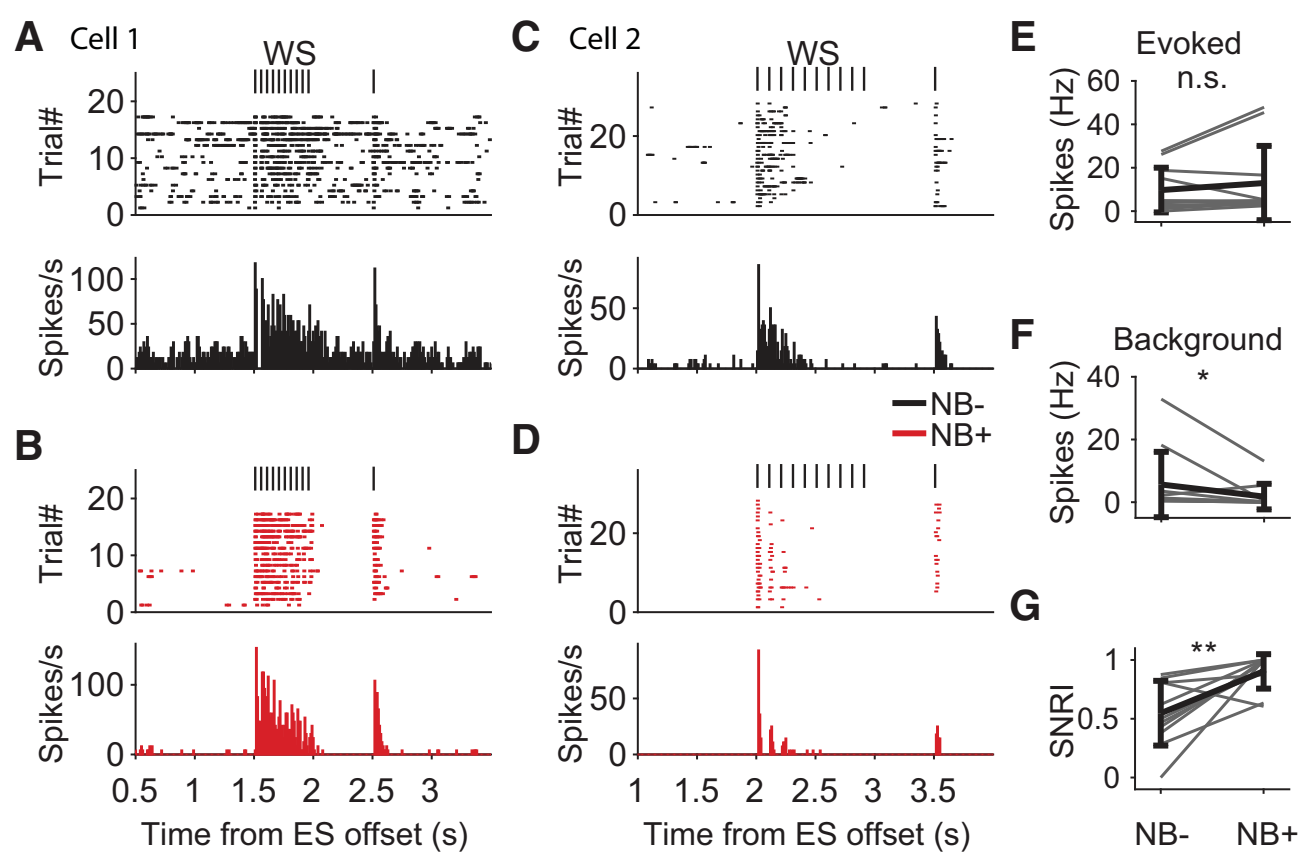

Figure 2. NB stimulation is increasing the SNR of sensory-evoked spike responses. $\boldsymbol{A}-\boldsymbol{D}$, Spontaneous and the sensory-evoked firing response of two barrel cortex cells recorded at depths of 356 (left) and $410 \mu \mathrm{m}$ from pia, before $(\boldsymbol{A}, \boldsymbol{C})$ and after $(\boldsymbol{B}, \boldsymbol{D})$ NB stimulation. Top: Raster plots. Bottom, PSTHs. Time 0 marks the offset of NB stimulation. $\boldsymbol{E}$, Spike rate of sensory evoked response during $500 \mathrm{~ms}$ of stimulus train for 11 cells. Background spike rate was subtracted. $\boldsymbol{F}$, Spike rate of background spikes during $500 \mathrm{~ms}$ before sensory stimulation onset. $G$, SNR index. In $\boldsymbol{E}-\boldsymbol{G}$, gray lines mark single neurons, black lines mark population mean \pm SD. WS, Whisker stimulation. ${ }^{*} p<0.05$, ${ }^{* *} p<0.01$, n.s., non significant, Wilcoxon's signed-rank test, $n=11$ cells.

On average, there was no change in firing response magnitude following NB stimulation (Fig. $2 E$, from $9.72 \pm 10.3$ to $12.95 \pm$ 17.11 spikes/s, $p=0.17$, Wilcoxon's signed-rank test, $n=11$ ). However, the mean background activity (see Materials and Methods) was drastically and significantly reduced, reflecting the suppression of spontaneous firing (Fig. $2 F$, from $5.64 \pm 10.42$ to $1.78 \pm 4.08$ spikes/s, Wilcoxon's signed-rank test, $p=0.02, n=11$ ).

To quantify the SNR, we calculated an SNR index (Vinck et al., 2015) (see Materials and Methods). Consistent with previous studies, the SNR index showed a marked increase following NB stimulation (from $0.54 \pm 0.27$ to $0.90 \pm 0.14$, Wilcoxon's signedrank test, $p=0.007, n=11$, Fig. $2 G$ ). Because there was no change in the signal (the sensory response), the main contribution to the improved SNR is the reduced noise (background firing). To better understand these effects at the subthreshold level, we made intracellular recordings.

\section{NB stimulation suppresses the spontaneous synaptic activity} We recorded the $V_{\mathrm{m}}$ of 17 barrel cortical cells from 13 animals, 1-3 cells per animal, using whole-cell patch clamp. All cells except one were located at a depth of 300-500 $\mu \mathrm{m}$, corresponding to layer 4. An example from one cell (recording depth $356 \mu \mathrm{m}$ ) is shown in Figure $3, A-C$. These $V_{\mathrm{m}}$ recordings demonstrate the effects of NB stimulation (Fig. $3 A$ ). Following NB stimulation, the mean $V_{\mathrm{m}}$ became more hyperpolarized (Fig. $2 B$ ) and the SD decreased (Fig. 3C). Across the population of cells, the mean $V_{\mathrm{m}}$ averaged along $2 \mathrm{~s}$ was hyperpolarized following NB stimulation from $-59.44 \pm 7.91 \mathrm{mV}$ to $-61.99 \pm 7.90 \mathrm{mV}$ (Fig. 3D, Wilcoxon's signed-rank test, $n=17, p=0.0004)$. The trial-to-trial variability quantified by the $V_{\mathrm{m}}$ SD decreased following NB stimulation from $5.04 \pm 2.08 \mathrm{mV}$ to $3.47 \pm 1.99 \mathrm{mV}$ (Fig. $3 E$, Wilcoxon's signed-rank test, $n=17, p=0.0003$ ).

Electrical stimulation of the NB leads to global modulation due to the relatively wide axonal spread of NB cells. Moreover, the electrical stimulation nonselectively activates different NB cell populations; for example, glutamatergic, cholinergic, and GABAergic cells, along with a possible activation of fibers of passage or nearby cells. To stimulate only local cholinergic inputs, we used ChAT-ChR2 mice, which express ChR2 in cholinergic neurons (Fig. 4A). First, to verify that cholinergic cells expressed ChR2, we recorded extracellularly in the NB of ChAT-ChR2 mice using an "optopatcher" (Katz et al., 2013), which enables simultaneous intracellular or extracellular recording and light emission through the same pipette (see illustration in Fig. 4B). We recorded juxtacellularly three single units (S.U.) that responded to optogenetic stimulation. An example from one cell (recording depth $4780 \mu \mathrm{m}$ ) is shown in Figure 4, $C-E$. We stimulated the cell with different frequencies between 1 and $20 \mathrm{~Hz}$ and different pulse durations between 2 and $20 \mathrm{~ms}$. The cell responded with a single spike locked to the light pulses, as can be seen in the raw data trace in Fig. $4 C$ and in the raster and PSTH plots in Fig. 4, D and $E$. At frequencies above $5 \mathrm{~Hz}$, the ability of the cells to follow the stimulus train decreased. At $15 \mathrm{~Hz}$, the cell's responses from the third pulse onward were less reliable. This is consistent with previously reported characteristics of $\mathrm{NB}$ cholinergic cells (Kalmbach et al., 2012). Next, we recorded the $V_{\mathrm{m}}$ of cortical neurons using whole-cell patch pipettes as described above and optogenetically activated the local cholinergic fibers innervating the cortex by $3 \mathrm{~s}$ of continuous optogenetic stimulation emitted from a fiber optic placed $<1 \mathrm{~mm}$ above the cortical surface. We recorded the $V_{\mathrm{m}}$ of 11 barrel cortical cells in 5 animals, $1-3$ cells per animal. All cells were located at depths of 350-500 $\mu \mathrm{m}$, corresponding to layer 4. An example of the effect of optogenetic stimulation on ongoing activity of a cell recorded at depth of 377 $\mu \mathrm{m}$ is shown in Figure 5, $A-C$. Similar to the effects of NB activation with electrical stimulation, during optogenetic stimulation, the mean $V_{\mathrm{m}}$ became more hyperpolarized (Fig. $5 \mathrm{~B}$ ) and the SD decreased (Fig. $5 C$ ). In the population of cells, the mean $V_{\mathrm{m}}$ hyperpolarized significantly during optogenetic stimulation, from $-58.58 \pm 4.13 \mathrm{mV}$ to $-60.49 \pm 3.71 \mathrm{mV}$ (Fig. $5 D, p=$ 
0.0029. Wilcoxon's signed-rank test, $n=$ 11 cells). The trial-to-trial variability quantified by the $V_{\mathrm{m}}$ SD decreased significantly during optogenetic stimulation from $2.68 \pm 1.29 \mathrm{mV}$ to $1.96 \pm 1.08 \mathrm{mV}$ (Fig. $5 E, p=0.042$. Wilcoxon's signedrank test, $n=11$ ). In contrast to the effect of NB electrical stimulation, here, the changes in $V_{\mathrm{m}}$ dynamics following light onset started earlier. In some cells, optogenetic stimulation evoked a transient fast depolarization 4-11 ms following light onset, matching nicotinic receptor activation (see Fig. $5 A-C$ the early fast depolarization in the individual and average traces).

\section{Cholinergic activation reduces PSP frequency and amplitude}

For a closer inspection of the spontaneous activity, we detected PSPs (see Materials and Methods; an example of the automatic detection for two trials from a cell recorded at depth of $468 \mu \mathrm{m}$ is shown in Fig. 6A). The amplitude distribution of spontaneous PSPs from one cell before and after NB stimulation demonstrates the decreased amplitude of spontaneous PSPs (Fig. 6B). The inset shows the median PSP amplitude and confidence interval for this cell. Accordingly, the population analysis has revealed that, following NB stimulation, both the rate and the amplitude of spontaneous PSPs were diminished (from $5.46 \pm$ $2.33 \mathrm{~Hz}$ to $4.01 \pm 3.21 \mathrm{~Hz}, p=0.0026$, and $6.47 \pm 2.25 \mathrm{mV}$ to $4.12 \pm 1.8 \mathrm{mV}, p=$ 0.0006 , respectively, Wilcoxon's signedrank test, $n=17$, Fig. $6 C, D$ ). We verified that the reduced rate of PSPs was not due to detection false negatives.

Similar to NB stimulation, a suppression of spontaneous activity during optogenetic stimulation was indicated by a reduced rate and amplitude of spontaneous PSPs (from $2.95 \pm 2.47 \mathrm{~Hz}$ to $1.99 \pm$ $2.4 \mathrm{~Hz}, p=0.0049$, and from $4 \pm 1.52 \mathrm{mV}$ to $2.93 \pm 0.7 \mathrm{mV}, p=0.004$, respectively. Wilcoxon's signed-rank test, $n=11$, Fig. $6 E-G)$.

\section{Cholinergic suppression of spontaneous synaptic activity in awake animals}

Anesthesia has profound effects on neuronal activity, especially in the cortex. To address the possibility that the ability of cholinergic inputs to modulate cortical activity is restricted to the state of anesthesia, we optogenetically activated local cholinergic fibers in the barrel cortex of awake head-fixed ChAT-ChR2-EYFP mice. We recorded 7 L4 cells in 2 animals, 3-4 cells per animal, while monitoring the animals' locomotion and whisking (method is illustrated in Fig. 7A). In these experiments, we only explored the effects of optogenetic stimulation on the spontaneous activity. An example from a cell recorded at depth of $341 \mu \mathrm{m}$ is shown in Figure $7, B-D$, demonstrating the effects of optogenetic stimula-
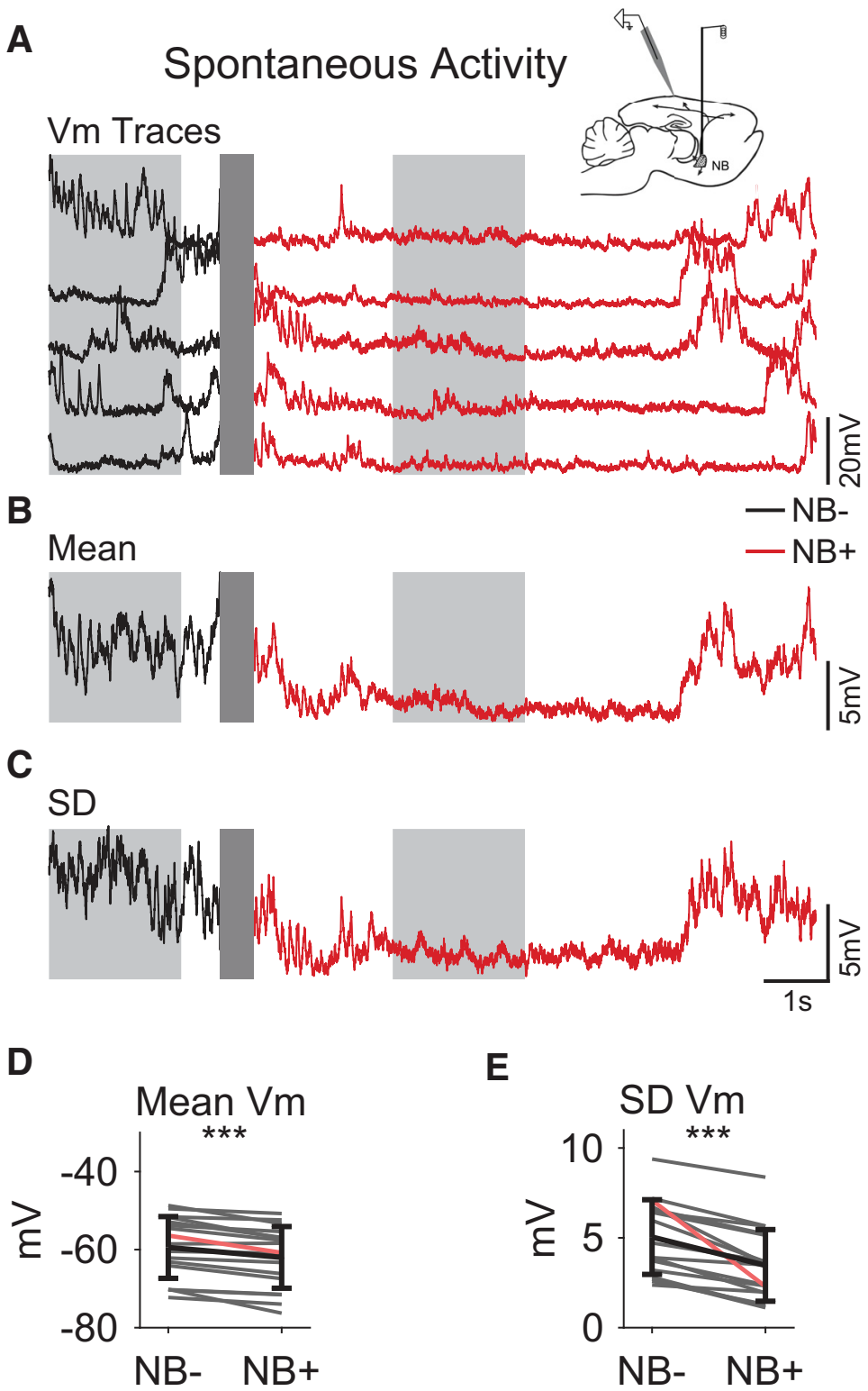

Figure 3. NB electrical stimulation reduces $V_{\mathrm{m}}$ synaptic fluctuations. $\boldsymbol{A}-\boldsymbol{C}$, Spontaneous $V_{\mathrm{m}}$ traces $(\boldsymbol{A})$, mean $(\boldsymbol{B})$ and SD $(\boldsymbol{C})$ of an lines mark single neurons (the example cell is in color), black lines mark population mean $\pm S D .{ }^{* * *} p<0.001$, n.S., non significant. $\boldsymbol{D}, \boldsymbol{E}$, Wilcoxon's signed-rank test, $n=17$ cells.

tion on the spontaneous activity. Similar to the anesthetized mice, the changes in $V_{\mathrm{m}}$ dynamics started after light onset and lasted at most $1 \mathrm{~s}$ after light offset. Similar to the anesthetized preparation, we observed a suppression of spontaneous activity during optogenetic stimulation in the single trials (Fig. $7 B$ ). The mean $V_{\mathrm{m}}$ became more hyperpolarized (Fig. $7 C$ ) and the SD decreased (Fig. 7D).

To optogenetically activate neurons, we used bare optical fiber to shine light over the cortex. The animal might have visually perceived light scattered from the skull and the head bar. To test the possibility that seeing the light made the animal whisk and whisking shifted the cortical state, we examined the pattern of whisking before and during the light. Examples of single whisking traces from one animal and the mean trace is shown in Figure $7 E$. Comparing the average power of the whisking signal (see Mate- 
A

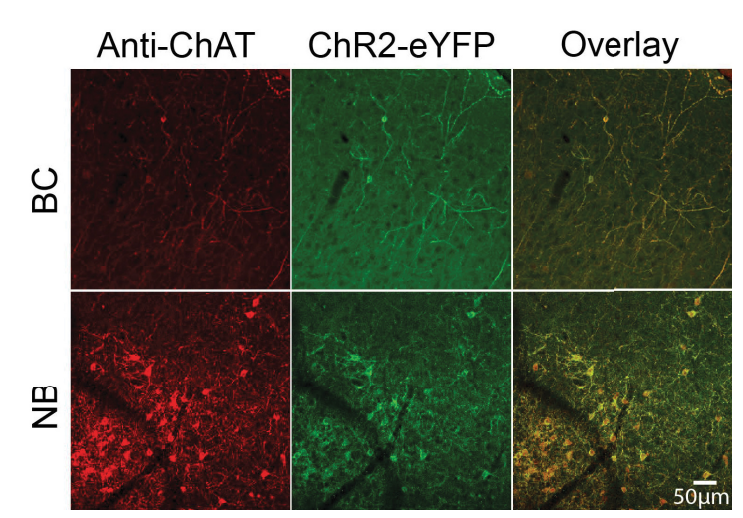

B

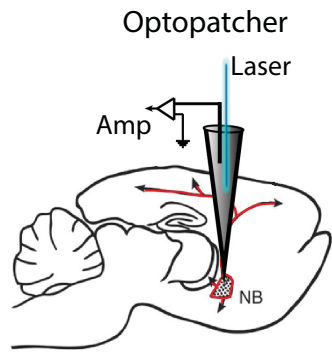

C - Optogenetic stimulation

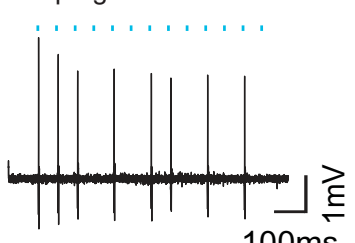

D
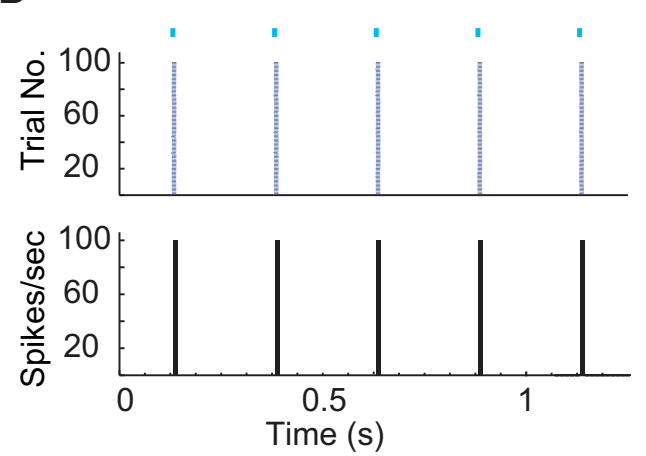

E
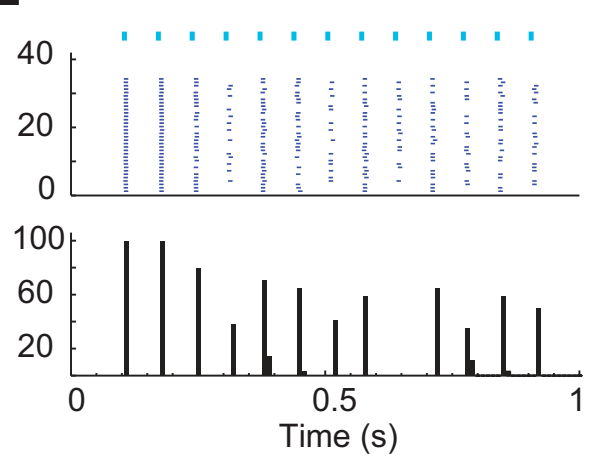

Figure 4. Selective optogenetic activation of NB cells suspected as cholinergic. $A$, Expression of ChR2 in the barrel cortex and NB of ChAT-ChR2 mice. Left, ChAT immunostaining. Middle, EYFP-ChR2 fusion protein. Right, Overlay. EYFP fluorescence was enhanced with anti-YFP antibody. bregma $-0.9 \mathrm{~mm}$. Scale bar, $50 \mu \mathrm{m}$. $\boldsymbol{B}, \mathrm{Schematic}$ illustration of the recording method with an "optopatcher" inserted into the NB. C, Single trace showing the response of S.U. recorded at depth of $4780 \mu \mathrm{m}$ below pial surface to a $15 \mathrm{~Hz}$ optogenetic stimulation. Cyan squares mark the optogenetic stimulation with a $10 \mathrm{~ms}$ pulse duration. $\boldsymbol{D}, \boldsymbol{E}$, Raster (top) and PSTH (bottom) for the response of the same S.U. in $\boldsymbol{C}$ to $5 \mathrm{~Hz}$ and $15 \mathrm{~Hz}$ stimuli, respectively.

rials and Methods) before and during the optogenetic stimulus showed that light did not change whisking pattern (Fig. $7 F$, from $12.18 \pm 14.93$ a.u. to $12.45 \pm 25.14$ a.u., $p=1$, Wilcoxon's signed-rank test, $n=5$ animals). In the population of cells, the mean $V_{\mathrm{m}}$ hyperpolarized significantly during optogenetic stimulation, from $-52.56 \pm 21.02 \mathrm{mV}$ to $-54.41 \pm 21.22 \mathrm{mV}$, and the variability in $V_{\mathrm{m}}(\mathrm{SD})$ decreased from $7.8 \pm 3.71 \mathrm{mV}$ to $6.22 \pm$ $2.67 \mathrm{mV}$ (Fig. 7G, H, $p=0.015, p=0.047$, respectively, Wilcoxon's signed-rank test, $n=7$ cells). The frequency and amplitude of spontaneous events were reduced from $5.66 \pm 2.55 \mathrm{~Hz}$ to $3.96 \pm 2.81 \mathrm{~Hz}$ and from $7.06 \pm 1.69 \mathrm{mV}$ to $4.68 \pm 1.14 \mathrm{mV}$, respectively (Fig. $7 I, J, p=0.015$ and $p=0.031$, respectively, Wilcoxon's signed-rank test, $n=7$ ).

Following validation that the shift in cortical state induced by optogenetic stimulation of cholinergic projections in the awake brain resembles that seen during light anesthesia, we quantified the change in SNR in anesthetized animals.

\section{NB stimulation increases the SNR of subthreshold sensory responses}

We sought to characterize the effect of NB activation on the sensory evoked subthreshold responses to reveal the underlying mechanism for the improved response SNR shown in Figure 2. To test the effect of cholinergic activation on response amplitude and adaptation, we delivered repeating trains of whisker stimuli $(10 \mathrm{~Hz}$ or $20 \mathrm{~Hz})$ with an additional identical test stimulus intro- duced $500 \mathrm{~ms}$ after the last stimulus in the train to examine the recovery from adaptation. An example from a cell recorded at depth of $345 \mu \mathrm{m}$ is shown in Figure $8, A-D$, demonstrating the effects of NB stimulation on sensory-evoked responses. Following NB stimulation, the mean $V_{\mathrm{m}}$ became more hyperpolarized, the sensory responses became more obvious on each stimulation (Fig. 8C), and the trial-to-trial SD decreased (Fig. 8D). At the population level and similar to trials in which whisker stimulation was absent (Fig. 3), the mean $V_{\mathrm{m}}$ during the sensory response hyperpolarized following NB stimulation from $-54.35 \pm 8.13$ $\mathrm{mV}$ to $-55.71 \pm 8.48 \mathrm{mV}$ (Fig. $9 A$, Wilcoxon's signed-rank test, $n=17, p=0.0035$ ). The trial-to-trial variability quantified by the $V_{\mathrm{m}}$ SD during the sensory response decreased following NB stimulation from $4.22 \pm 1.57 \mathrm{mV}$ to $3.76 \pm 1.89 \mathrm{mV}$ (Fig. 9B, Wilcoxon's signed-rank test, $n=17, p=0.031)$. Similar effects were seen during optogenetic activation of local cholinergic fibers, as demonstrated in an example cell in Figure 8, E-H. During optogenetic stimulation, the mean $V_{\mathrm{m}}$ of the sensory response became more hyperpolarized (Fig. 8G) and the SD decreased (Fig. $8 H$ ). At the population level, the mean $V_{\mathrm{m}}$ during the sensory train stimulation hyperpolarized significantly during optogenetic stimulation, from $-56.32 \pm 4.9 \mathrm{mV}$ to $-58.33 \pm 4.45 \mathrm{mV}$ (Fig. $9 H, p=0.001$. Wilcoxon's signed-rank test, $n=11$ cells). Conversely, the trial-to-trial variability nonsignificantly decreased during optogenetic stimulation (from $2.27 \pm 0.63 \mathrm{mV}$ to $1.95 \pm$ $0.62 \mathrm{mV}$ during the sensory train Fig. 9I, $p=0.1$. Wilcoxon's 
signed-rank test, $n=11$ ). These changes seen in the $V_{\mathrm{m}}$ mean and SD during the sensory response are similar to those seen during spontaneous activity, suggesting that NB stimulation or optogenetic activation of cholinergic fibers do not alter feedforward sensory inputs.

So far, we have seen that activation of cholinergic inputs has a differential effect on spontaneous and sensory-evoked activities. Whereas spontaneous synaptic activity was reduced by activation of cholinergic inputs, the amplitude of the sensory response to the whisker stimuli did not change, suggesting that the subthreshold SNR increased. To confirm this, we computed the signal amplitude and noise amplitude of sensory responses (see Materials and Methods) and the squared ratio between them gave the SNR. Following NB stimulation, the subthreshold SNR was increased by $42 \%$ (from $0.47 \pm 0.32$ to $0.84 \pm 0.67 ; p=0.008$, Wilcoxon's signed-rank test, $n=17$, Fig. 9C). In agreement with our extracellular results, this was due to no change in signal amplitude (from $2.12 \pm 1.01 \mathrm{mV}$ to $2.23 \pm 1.38 \mathrm{mV}, p=$ 0.72 , Wilcoxon's signed-rank test, $n=$ 17, Fig. 9D), whereas the noise amplitude decreased significantly (from $3.27 \pm 1.04 \mathrm{mV}$ to $2.71 \pm 1.24 \mathrm{mV}, p=$ 0.001 , Wilcoxon's signed-rank test, $n=$ 17, Fig. 9E).

Similar to NB activation, optogenetic stimulation increased the whisker-evoked SNR by $115 \%$ (from $0.89 \pm 0.7$ to $1.96 \pm$ $1.96 p=0.024$, Wilcoxon's signed-rank test, $n=11$, Fig. $9 \mathrm{~J}$ ). This was due to no change in signal amplitude (from $1.37 \pm$ $1.30 \mathrm{mV}$ to $1.21 \pm 0.87 \mathrm{mV}, p=0.76$, Wilcoxon's signed-rank test, $n=11$, Fig. $9 \mathrm{~K}$ ) and a prominent reduction in the noise amplitude (from $1.41 \pm 0.87 \mathrm{mV}$ to $0.97 \pm 0.48 \mathrm{mV}, p=0.003$, Wilcoxon's signed-rank test, $n=11$, Fig. $9 L$ ).

When inspecting individual responses to each one of the stimuli during the train of whisker stimuli, we observed that NB or optogenetic stimulation had negligible effects on the adaptation magnitude or its pattern (Figs. $9 F, G, M, N$ ). This was quantified by calculating the AAR (see Materials and Methods) from the averaged individual PSPs that were evoked by stimulation. We revealed no significant changes in either the whisker-evoked response amplitude (Figs. 9F, M, $p>0.1$ following NB stimulation and $p>0.07$ during optogenetic stimulation, two-way repeatedmeasures ANOVA with post hoc Tukey comparisons, $n=17$ and $n=11$, respectively) or the AAR for both types of stimulation (Figs. $9 G, N, p=0.6$ following NB stimulation and $p=1$ during optogenetic stimulation, Wilcoxon's signed-rank test, $n=17$ and $n=11$, respectively).

In short, cholinergic modulation increases the sensory response SNR mainly by suppression of ongoing synaptic activ- ity while only slightly affecting the sensory evoked responses or adaptation pattern.

NB stimulation decouples the $V_{\mathrm{m}}$ and LFP signals and reduces the noise correlations

LFP amplitude is widely used as an indication of population synchrony, where large-amplitude LFP fluctuations are associated with high synchrony and a "flat" LFP is associated with a decorrelated population activity. In our recordings, we observed decreased LFP amplitude following NB stimulation, along with decreased synaptic activity in individual cells. To find out how activation of cholinergic input affects the correlation in the local network, we made simultaneous recordings of $V_{\mathrm{m}}$ and LFP.

Simultaneous nearby $V_{\mathrm{m}}$-LFP recordings $(<500 \mu \mathrm{m})$ were recorded with electrical NB stimulation $(n=11$ recordings from 8 animals) and with optogenetic stimulation $(n=9$ recordings in 
A
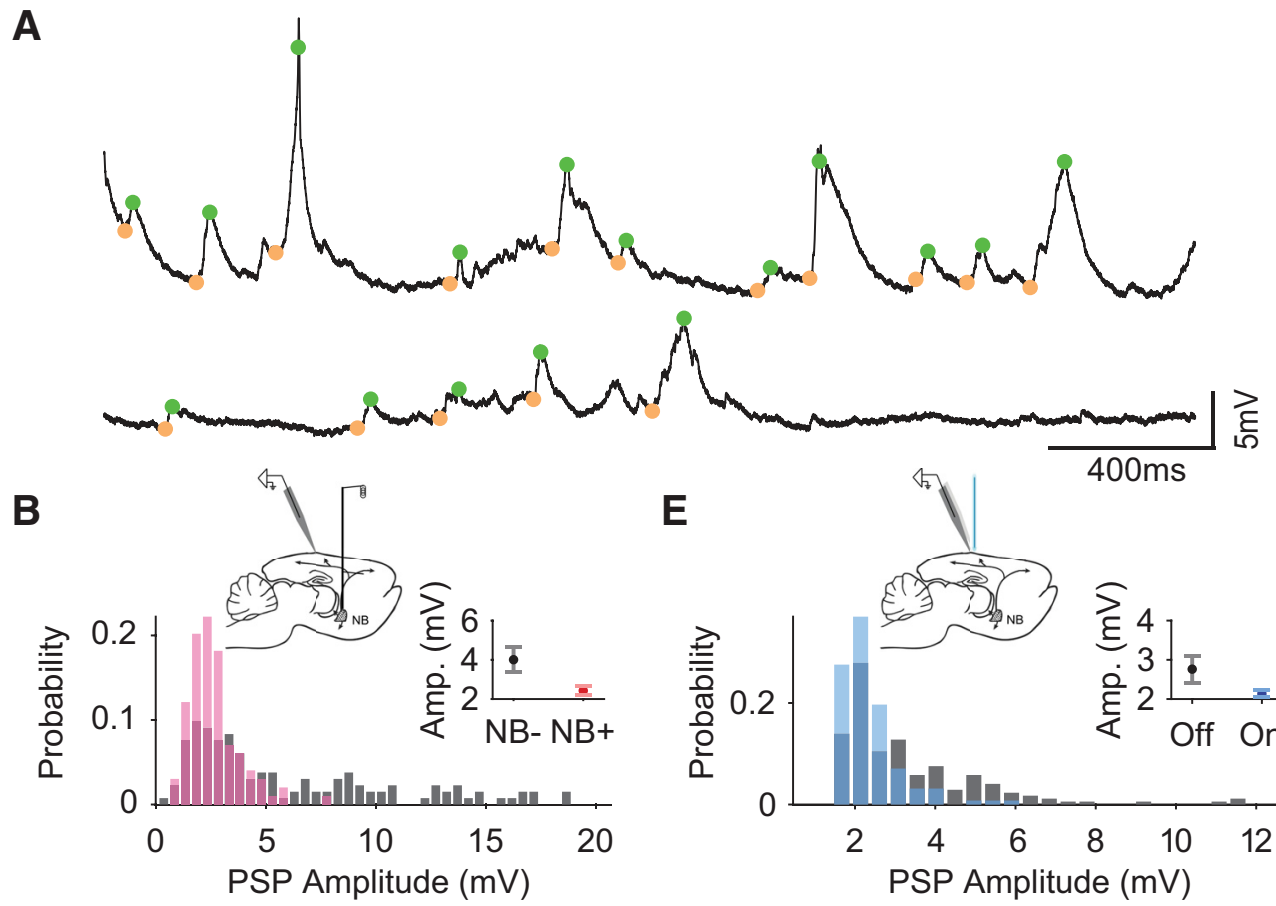

C

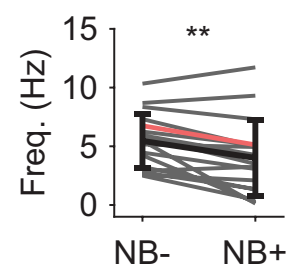

D

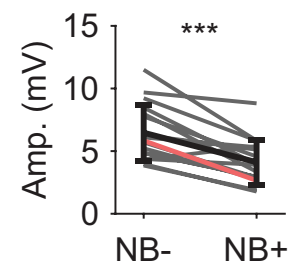

$\mathbf{E}$

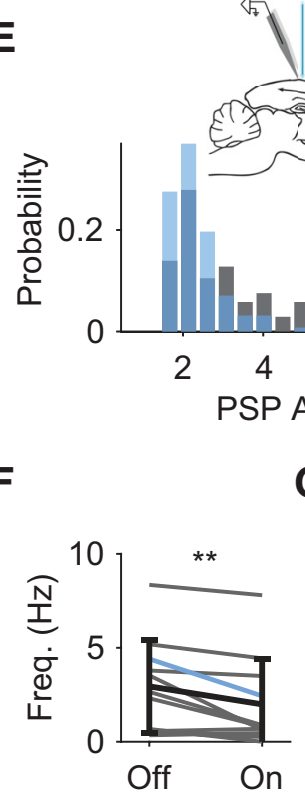

$\mathbf{F}$

G

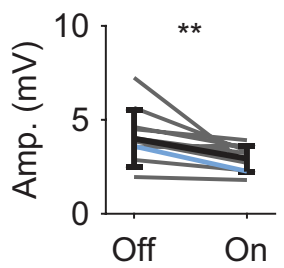

Figure 6. Cholinergic activation reduces the amplitude and rate of synaptic events. $A$, Examples for detection of spontaneous PSPs from a cell recorded at depth of $468 \mu \mathrm{m}$. Light dots mark PSP onset and dark dots mark PSP peak. B, Histogram of PSPs amplitude from one cell (same cell as in Fig. $3 A-C$ ) before (black) and after (red) NB stimulation. The inset shows the median amplitude for this cell with confidence intervals. C, Frequency of spontaneous PSPs. D, Amplitude of spontaneous PSPs. Gray lines mark single neurons (the example cell is in color), black lines mark population mean $\pm S D$. ${ }^{* *} p<0.01,{ }^{* * *} p<0.001$, Wilcoxon's signed-rank test, $n=17$. $\boldsymbol{E}-\mathbf{G}$, Same as $\boldsymbol{B}-\boldsymbol{D}$ but before and during optogenetic stimulation, Wilcoxon's signed-rank test, $n=11$ cells.

5 animals). An example of paired $V_{\mathrm{m}}$-LFP recordings demonstrates high correlation between these signals during spontaneous and sensory-evoked activities in the absence of cholinergic activation ( for before NB stimulation, see Fig. 10A, C; for before optogenetic stimulation, see Fig. $11 A, C)$. Similar to previous studies, the two signals displayed opposite polarities. Electrical stimulation of the NB (Fig. 10B,D) or local illumination of the cortex in a ChAT-ChR2 mouse (Fig. $11 B, D$ ) reduced the correlation between the two signals, as can be observed in the raw recordings. To quantify the effect of NB or optogenetic stimulation on the relationships between the two signals, we calculated both the raw cross-correlation and the noise correlations during ongoing and sensory-evoked activities (see Materials and Methods). The average raw and noise correlations from the same cells demonstrate a prominent decline in $V_{\mathrm{m}}$-LFP correlation following NB electrical or local optogenetic stimulation during spontaneous activity (Figs. $10 E, F, 11 E, F$ ). That $\mathrm{NB}$ and optogenetic stimulation similarly reduced the raw and noise correlations indicates that these stimuli did not introduce strong correlations during ongoing activity.

Similar results were observed at the population level, where we took the absolute values of the $V_{\mathrm{m}}$-LFP correlation at zero time lag (Pearson correlations) and plotted these values for individual recordings. Following NB stimulation, the spontaneous raw cor- relations decreased from $0.17 \pm 0.10$ to $0.08 \pm 0.08$ and the noise correlations decreased from $0.18 \pm 0.11$ to $0.09 \pm 0.08$ (Fig. $10 \mathrm{~J}, K, p=0.024$ for both, Wilcoxon's signed-rank test, $n=11$ ). Following optogenetic stimulation, the spontaneous raw correlations decreased from $0.23 \pm 0.17$ to $0.09 \pm 0.06$ and the noise correlations decreased from $0.24 \pm 0.18$ to $0.10 \pm 0.09$ (Fig. $11 \mathrm{~J}, K, p=0.039$ and $p=0.027$, respectively, Wilcoxon's signedrank test, $n=9$ ).

During the sensory evoked activity, raw correlations (total correlations) remained high following NB stimulation or optogenetic stimulation, as seen for the example recordings (Figs. $10 G, 11 G)$, as well as for the total of 11 independent recordings (Figs. $10 L, 11 L$, from $0.43 \pm 0.15$ in control conditions to $0.40 \pm$ 0.18 following NB stimulation, $p=0.51$, and from $0.33 \pm 0.25$ to $0.34 \pm 0.24$ during optogenetic stimulation, $p=0.91$, Wilcoxon's signed-rank test, $n=11$ and $n=9$, respectively). However, $\mathrm{NB}$ or optogenetic stimulation induced marked reduction in the noise correlations, as observed both in the averaged correlation in the two examples (Figs. 10H, 11H) and when we took the absolute values of the Pearson correlations from all recordings (Figs. $10 M, 11 M$, from $0.25 \pm 0.10$ to $0.14 \pm 0.08, p=0.018$, for $\mathrm{NB}$ stimulation and from $0.25 \pm 0.20$ to $0.11 \pm 0.10, p=0.027$, for 
A

B

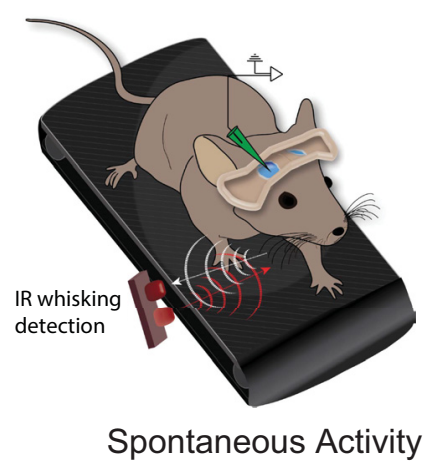

E

Single-trial whisking

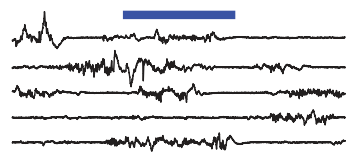

Mean Whisking

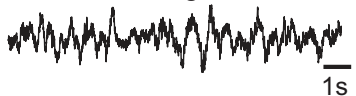

F

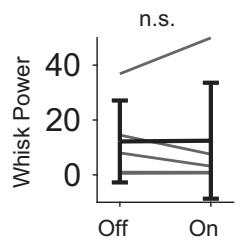

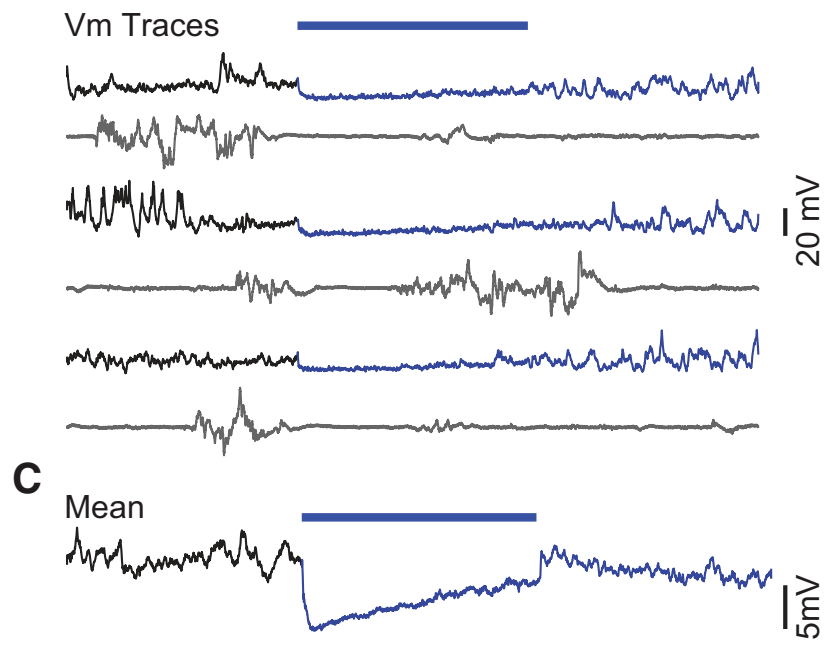

- Vm light off

— Vm light on

— Whisk

I

G

H
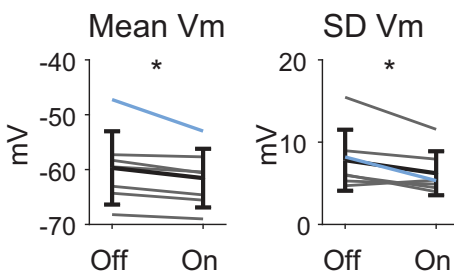

I

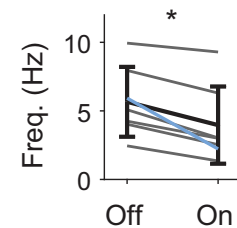

J

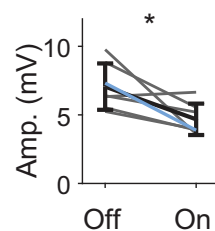

Figure 7. Light activation of local cholinergic inputs suppresses spontaneous synaptic activity in awake animals. $A$, Illustration of recording and optogenetic stimulation setup in awake head-fixed mice. $\boldsymbol{B}$, Spontaneous $V_{\mathrm{m}}$ (black) and whisking (gray) single traces recorded simultaneously together with mean $V_{\mathrm{m}}(\boldsymbol{C})$ and SD $V_{\mathrm{m}}(\boldsymbol{D})$ of the example neuron recorded at 341 $\mu \mathrm{m}$ below pial surface. G, Population mean $V_{\mathrm{m}}$. $\boldsymbol{H}$, Population $V_{\mathrm{m}} \mathrm{SD}$. E, Top, optogenetic stimulation squared pulse. Middle, Examples of single trials of whisking signal from one animal. Bottom, Whisking signal averaged over 60 trials. F, Whisk power. $\boldsymbol{I}$, Frequency of spontaneous PSPs. J, Amplitude of spontaneous PSPs. Blue bar marks optogenetic stimulation. Gray lines mark single neurons (the example cell is in color), black lines mark population mean \pm SD. ${ }^{*} p<0.05$, n.s., non significant, $G-J$, Wilcoxon's signed-rank test, $n=7$ cells, $\boldsymbol{F}$, Wilcoxon's signed-rank test, $n=5$ animals.

optogenetic stimulation; Wilcoxon's signed-rank test, $n=11$ and $n=9$, respectively).

The reduction in noise correlations between $V_{\mathrm{m}}$ and LFP is consistent with previously reported decreases in neuronal spike correlations during attention, NB stimulation, or cholinergic modulation (Cohen and Maunsell, 2009; Goard and Dan, 2009; Chen et al., 2015). Indeed, our recordings suggest that ongoing activity that is not locked to sensory stimulation introduced shared variability and that this type of activity is reduced due to NB stimulation or by activation of local cholinergic inputs.

Our final step was to check if NB or optogenetic stimulation affected the signal correlations (see Materials and Methods) of sensory response. In contrast to the drastic reduction of the noise correlation between $V_{\mathrm{m}}$ and LFP due to cholinergic activation (by electrical or optogenetic stimulation), the signal correlations were not affected by these manipulations. This is observed in the individual examples (Figs. 10I, 11I) showing that the crosscorrelations between the average $V_{\mathrm{m}}$ and LFP responses in the absence of cholinergic activation (black traces) are very similar in shape and magnitude to those obtained following NB stimulation (in red) and optogenetic stimulation (blue). That signal correlations were not affected by cholinergic activation is supported by the population data (Figs. $10 N, 11 N$, from $0.63 \pm 0.20$ to $0.59 \pm$ $0.23, p=0.413$, for $\mathrm{NB}$ stimulation and from $0.54 \pm 0.20$ to $0.55 \pm 0.21, p=0.652$, for optogenetic stimulation, Wilcoxon's signed-rank test, $n=11$ and $n=9$, respectively).

\section{Discussion}

In this study, our aim was to better understand the subthreshold basis of increased SNR of sensory responses and decorrelated cortical LFP that are induced by the NB and are correlated with attentional modulation (Herrero et al., 2008; Pinto et al., 2013).

We found that electrical stimulation of the NB or direct optogenetic activation of cholinergic cortical inputs increased the SNR of sensory responses and reduced the variance of the response and noise correlation of sensory responses while leaving the magnitude of sensory response and signal correlations unaffected. These effects are manifested by a marked reduction in the 


\section{Sensory evoked synaptic responses}

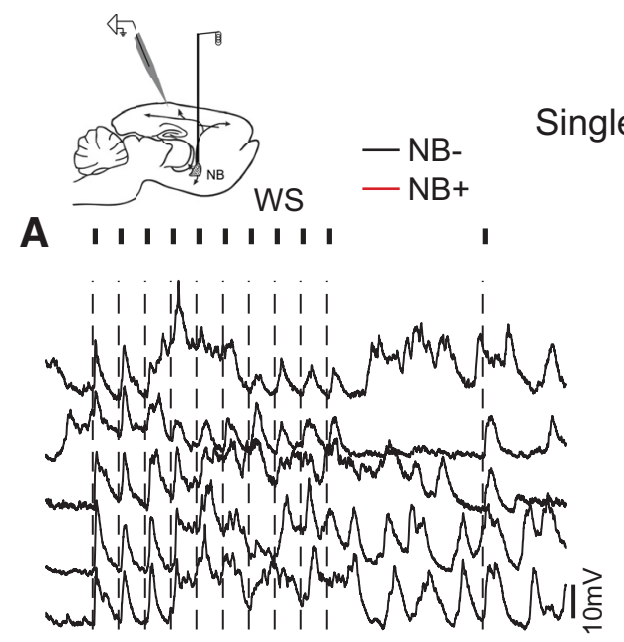

B

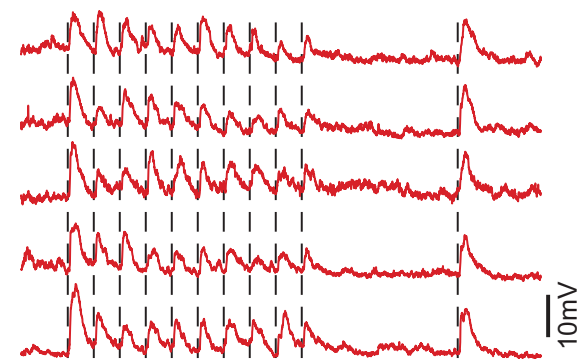

C

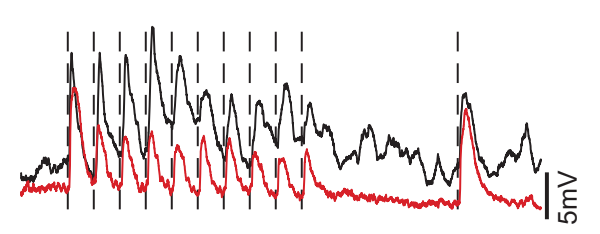

D

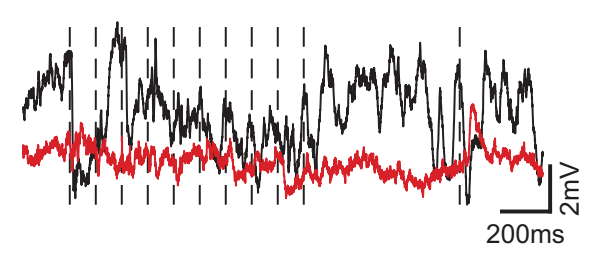

Mean

G

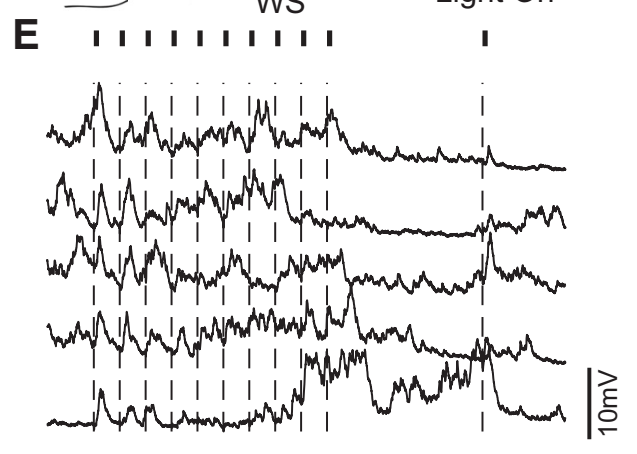

$\mathbf{F}$

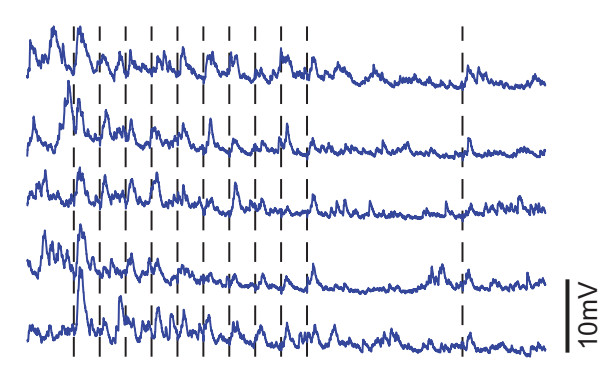

G

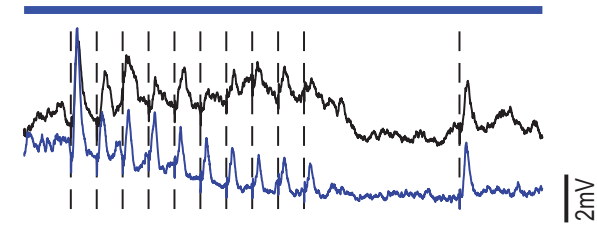

H

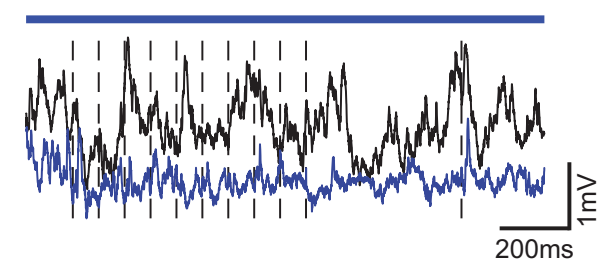

Figure 8. Cholinergic stimulation reduces the trial-to-trial variability of synaptic response to repetitive whisker stimulation. $A, B, V_{\mathrm{m}}$ traces of evoked responses to repetitive whisker stimulation $(10 \mathrm{~Hz}$ ) before $(\boldsymbol{A})$ and after $(\boldsymbol{B})$ NB stimulation. $\boldsymbol{C}$, Mean trace. $\boldsymbol{D}$, Traces SD. $\boldsymbol{E}-\boldsymbol{H}$, Same but in control and during optogenetic stimulation. WS, Whisker stimulation. Dashed lines mark whisker deflection onset.

rate, amplitude, and network correlation of ongoing synaptic activity. Importantly, we showed that optogenetic activation of cholinergic fibers in awake mice results in very similar effects on cortical activity as in anesthetized mice. The fact that the two methods of stimulation had such similar outcome points to a central role for ACh in direct modulation of cortical circuits by the NB. Our findings therefore strongly suggest that the major effect of cholinergic inputs is in suppression of ongoing cortical activity in the barrel cortex rather than in altering feedforward tactile inputs.

\section{Cortical desynchronization}

That activation of the cholinergic inputs in our study suppresses ongoing synaptic activity and leads to uncorrelated neuronal activity is in contrast to the prolonged depolarization and increased firing associated with a "desynchronized" or "high-conductance" state (Destexhe et al., 2003; Renart et al., 2010). Therefore, whereas reduced amplitude of LFP activity is usually regarded as one of the hallmarks of an active "desynchronized" brain state, our combined $V_{\mathrm{m}}$-LFP recordings indicate that reduced ampli- 


\section{Sensory evoked synaptic responses}
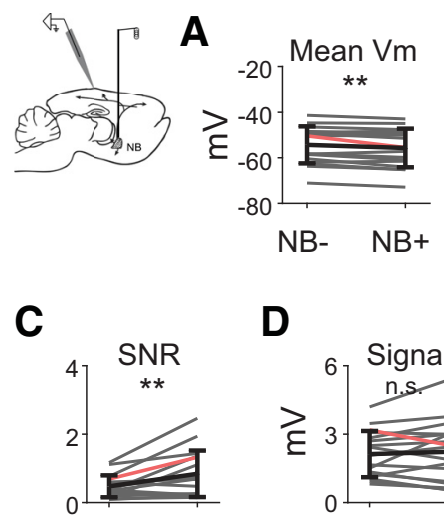

NB- $\mathrm{NB}+$

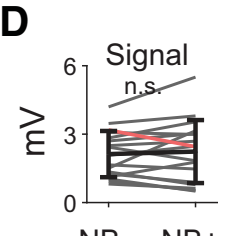

NB- NB+

$\mathbf{F}$

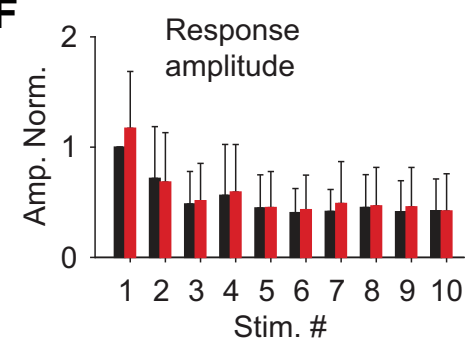

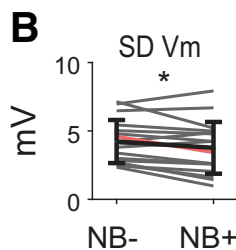

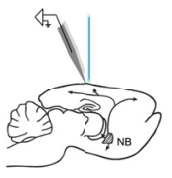

E

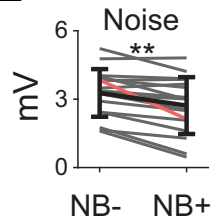

G

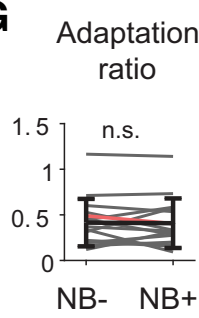

$\mathbf{J}$
H
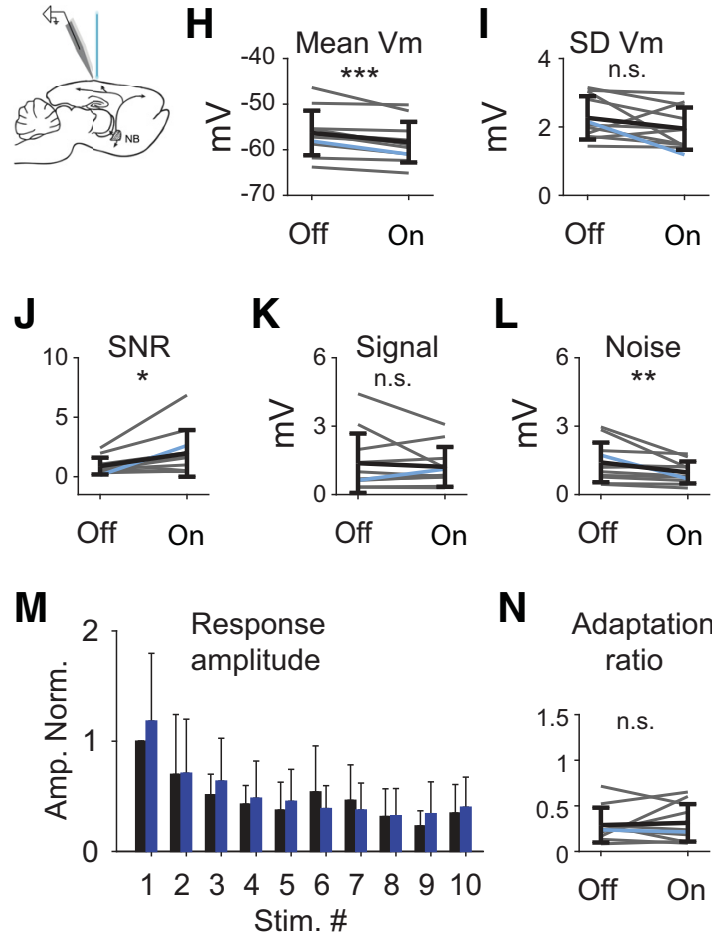

$\mathbf{N}$

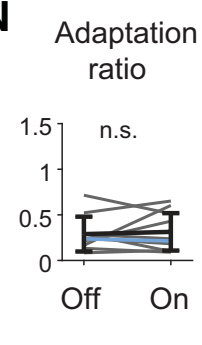

Figure 9. Cholinergic stimulation increases the SNR of subthreshold sensory responses. $\boldsymbol{A}$, Population mean $V_{\mathrm{m}}\left(V_{\mathrm{m}}\right)$ during whisker response. $\boldsymbol{B}$, Population $V_{\mathrm{m}} \mathrm{SD}$ during whisker response. $\boldsymbol{C}$, SNR. D, Signal-amplitude. $\boldsymbol{E}$, Noise amplitude. $\boldsymbol{F}$, Response amplitude along whisker stimulation train normalized to the first response in the train in control conditions. Lack of asterisk means no significant difference. G, AAR calculated as the averaged response amplitude of the last three whisker stimuli in the train divided by the amplitude of the response amplitude of the first stimulus. $\boldsymbol{H}-\boldsymbol{N}$, Same as in $\boldsymbol{A}-\mathbf{G}$, but in control and during optogenetic stimulation. Gray lines mark single neurons (the example cell is in color), black lines mark population mean \pm SD. ${ }^{*} p<0.05,{ }^{* *} p<$ $0.01,{ }^{* * *} p<0.001$, n.s., non significant. $\boldsymbol{F}$, Two-way repeated-measures ANOVA $(\boldsymbol{A}-\boldsymbol{E}, \boldsymbol{G})$, Wilcoxon's signed-rank test, $n=17$ cells. $\boldsymbol{M}$, Two-way repeated-measures ANOVA $(\boldsymbol{H}-\boldsymbol{L}, \boldsymbol{N})$, Wilcoxon's signed-rank test, $n=11$ cells.

tude of LFP activity following cholinergic activation reflects in fact a marked drop in cortical activity. Interestingly, recent studies in wakeful mice reported that, during periods of high arousal without locomotion, the $V_{\mathrm{m}}$ dynamics resembled those that we see following NB stimulation: hyperpolarized $V_{\mathrm{m}}$, reduced $V_{\mathrm{m}}$ variance, and suppression of low-frequency LFP fluctuations with no increase in high-frequency fluctuations. Furthermore, these studies have shown that this state is optimal for cue detection (Reimer et al., 2014; McGinley et al., 2015; Vinck et al., 2015).

\section{Cholinergic modulation of sensory response SNR}

As far as we know, this study is the first to report the effect of direct optogenetic activation of cholinergic inputs on subthreshold cortical dynamics during sensory stimulation. Our findings are consistent with a differential modulation of thalamocortical and intracortical pathways. We found no changes in sensory response amplitude and no significant change in cortical adaptation, in agreement with earlier studies suggesting that adaptation in this system is mostly governed by depression of thalamocortical synapses (Beierlein et al., 2003; Gabernet et al., 2005; Heiss et al., 2008). In contrast, adaptation to whisker stimulation was strongly reduced following application of cholinergic agonist (Castro-Alamancos and Gulati, 2014). Decrease in adaptation was reported previously also following activation of the reticular formation (Castro-Alamancos, 2004; Hirata and Castro-Alamancos, 2011). These differences may reflect different methods and ana- tomical sites for cholinergic activation or species differences (rats vs mice in our study). In agreement with suppression of intracortical connections reported in vitro, we found a decreased rate and amplitude of spontaneous PSPs following NB activation. The exact mechanisms underlying this suppression of spontaneous activity are yet to be determined. Plausible mechanisms are as follows: (1) cholinergic depression of glutamate release from intracortical synapses (Gil et al., 1997); (2) involvement of SOM interneurons in suppressing cortical activity (Chen et al., 2015; Muñoz et al., 2017; Urban-Ciecko et al., 2018); (3) suppression of cortical layer 5, which was shown to be the source of cortical spontaneous activity (Sakata and Harris, 2009; Beltramo et al., 2013); (4) cholinergic activation of L1 interneurons, which inhibit pyramidal neurons through $\mathrm{GABA}_{\mathrm{B}}$ (Brombas et al., 2014); (5) long-lasting inhibition by cholinergic activation of astrocytes, which in turn excite inhibitory interneurons (Pabst et al., 2016); (6) co-transmission of GABA and ACh from cholinergic terminals in the cortex (Saunders et al., 2015); and (7) long-lasting inhibition of excitatory neurons of L4 due to direct activation of muscarinic cholinergic receptors (Dasgupta et al., 2018). That cholinergic interneurons in layer $2 / 3$ mediate these effects is unlikely. These neurons are scarce and they were shown to have negligible effects on neighboring cells (von Engelhardt et al., 2007). Our findings are at odds with the work of Metherate and Ashe (1993), who showed that NB electrical stimulation in vivo induced a persistent depolarization and increased excitability in the rat auditory cortex by closing a $\mathrm{K}^{+}$-mediated hyperpolarizing 
A

SB- Spontaneous Activity

C Sensory-evoked Responses

WB-

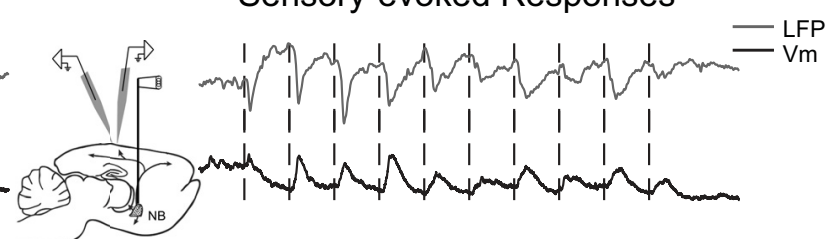

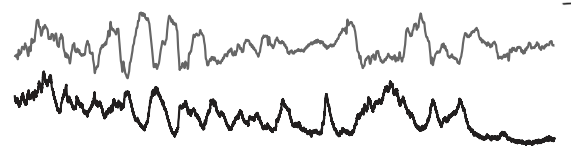

|

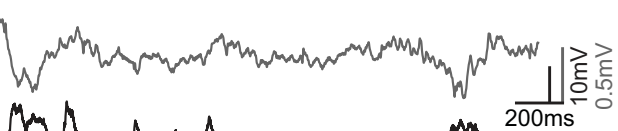

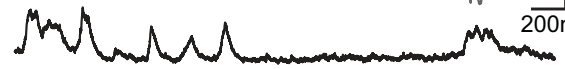

B NB+

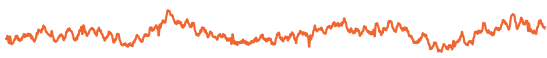

D

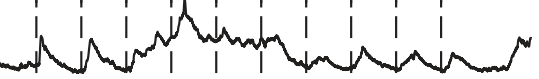
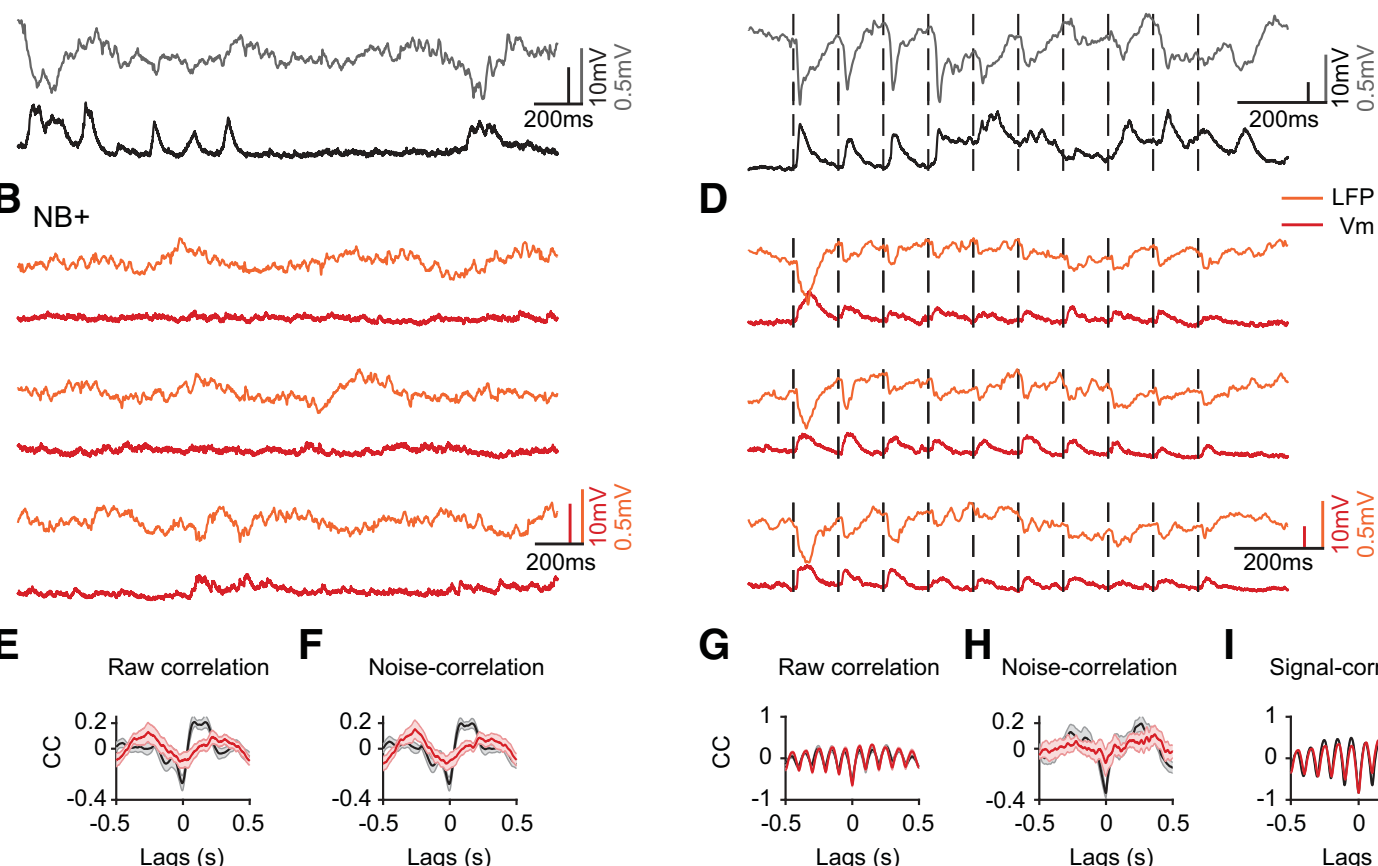

$\mathbf{F}$

Noise-correlation

G

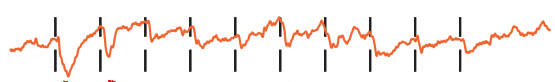

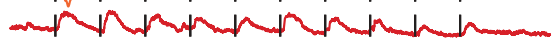

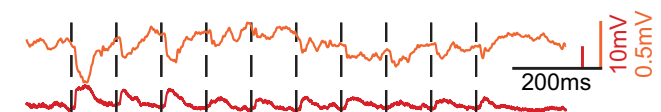

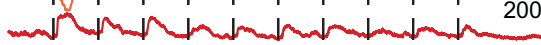

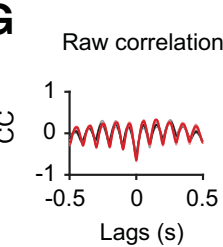

$\mathbf{H}$

Noise-correlation

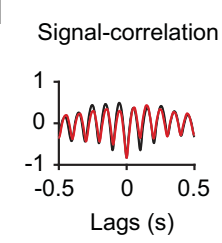

$\mathbf{J}$
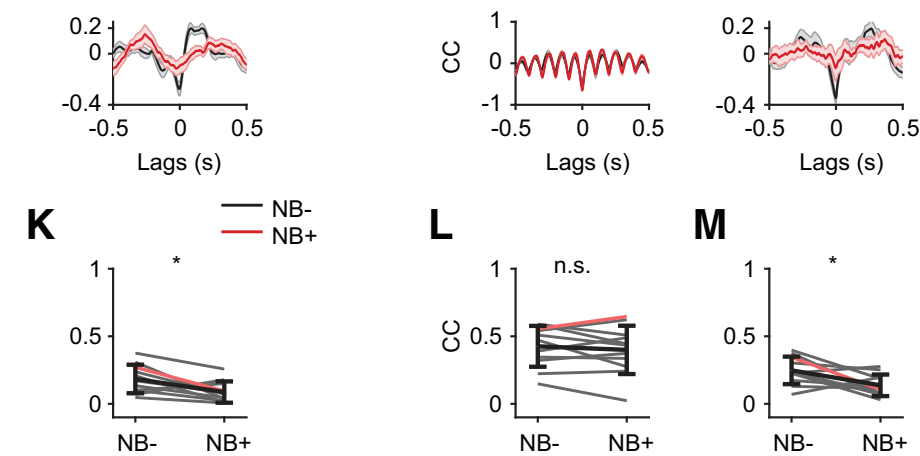

M
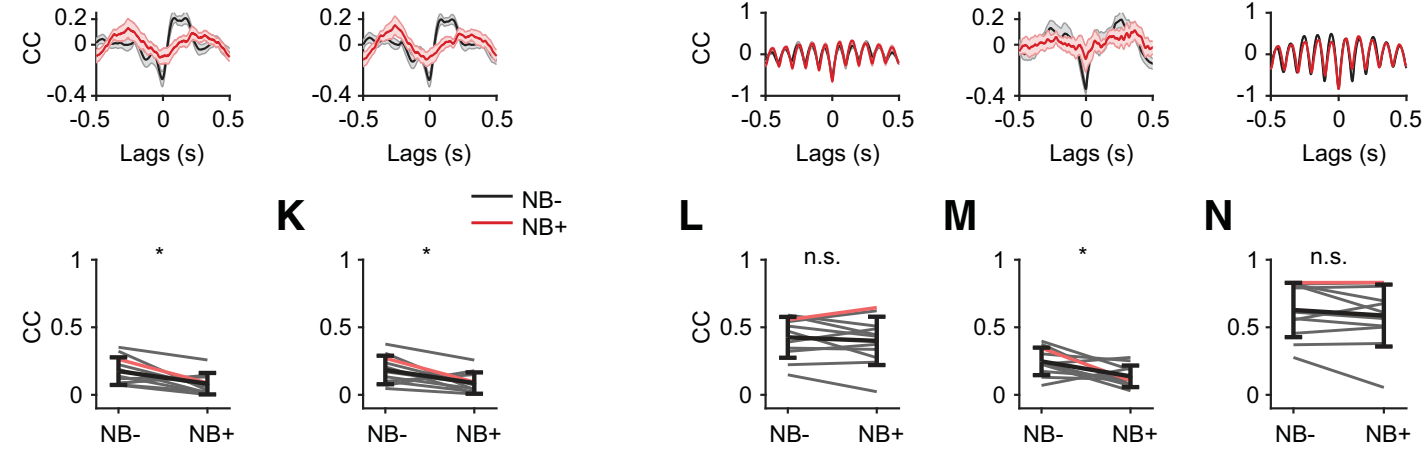

Figure 10. NB stimulation decorrelates $V_{\mathrm{m}}$-LFP activities in the local cortical network. $A, B$, Simultaneous $V_{\mathrm{m}}$ and nearby LFP recordings during spontaneous activity in control conditions $(\boldsymbol{A})$ and following NB stimulation $(\boldsymbol{B}) . \boldsymbol{C}, \boldsymbol{D}$, Same as $\boldsymbol{A}$ and $\boldsymbol{B}$ but for sensory-evoked responses. Dashed lines mark whisker deflections onset. $\boldsymbol{E}$, Spontaneous raw cross-correlations presented as mean \pm SEM. $\boldsymbol{F}$, Same as $\boldsymbol{E}$ but for noise correlations. $\boldsymbol{G}, \boldsymbol{H}$, Same as $\boldsymbol{E}$ and $\boldsymbol{F}$ but for sensory-evoked responses. $\boldsymbol{I}$, Signal correlations. $\boldsymbol{E}-\boldsymbol{I}$ were calculated from the same recording of $L F P-V_{\mathrm{m}}$ shown in $\boldsymbol{A}-\boldsymbol{D}$. J, Spontaneous zero-lag (Pearson) raw correlations for the population of $V_{\mathrm{m}}-L F P$ recordings. $K$, Spontaneous zero-lag (Pearson) noise correlations for the population of $V_{\mathrm{m}}-L F P$ recordings. $L, M$, Same as $\boldsymbol{J}$ and $\boldsymbol{K}$ but for sensory-evoked responses. $\boldsymbol{N}$, Zero-lag (Pearson) of signal correlations for the population of $V_{\mathrm{m}}$ - LFP recordings. Gray lines mark single neurons (example cell is in color), black lines mark population average. ${ }^{*} p<0.05$, n.s., non significant. Wilcoxon's signed-rank test, $n=11$ cells.

current. However, they recorded from more superficial layers than layer 4 and a different modality. Our results agree with the findings of Eggermann et al. (2014) showing that optogenetic stimulation of cholinergic NB neurons suppresses ongoing cortical activity in awake head-fixed mice. However, they only used mice with an inactivated thalamus. Interestingly, similar suppression of cortical ongoing synaptic activity but with a depolarized $V_{\mathrm{m}}$ and suppression of sensory-evoked responses was achieved with electrical stimulation of the brainstem reticular formation (Hirata and Castro-Alamancos, 2010, 2011). Last, in two recent studies (Pinto et al., 2013; Minces et al., 2017), local optogenetic activation of cholinergic axons pro- jecting to V1 led to: (1) increased spontaneous spikes across all layers in V1, (2) increased SNR due to increased signal amplitude with no change in the noise amplitude, and (3) a moderate decrease in noise correlations with no change in the signal correlations. The discrepancies might be a result of the different cortical areas studied or the use of different transgenic mouse lines (Kolisnyk et al., 2013).

The differential modulation of ongoing and sensory-evoked activities by NB activation observed in our study raises a difficulty. Recent studies have shown that the thalamic inputs account for only approximately half of the sensory-evoked responses in layer 4 , whereas the rest is provided by the cortical 
Spontaneous Activity

A

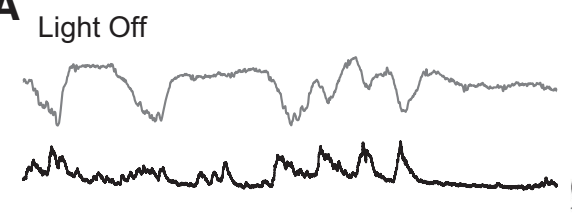

\section{Sensory-evoked Responses}

C
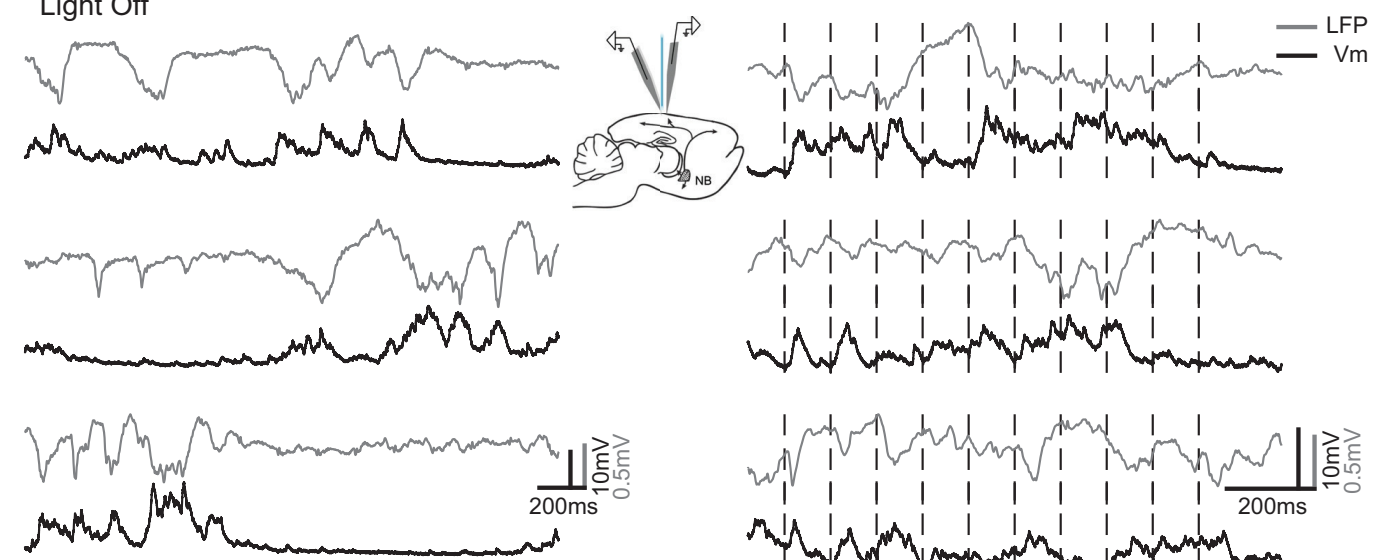

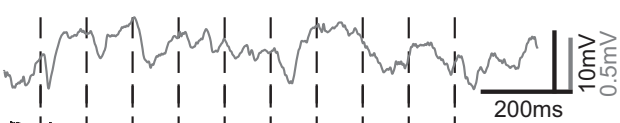

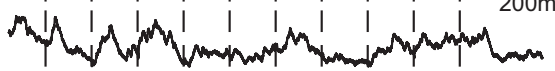

B

Light On
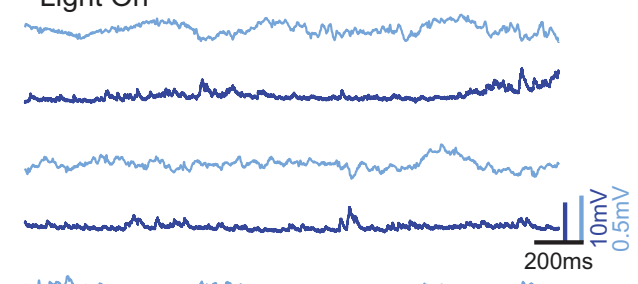

D

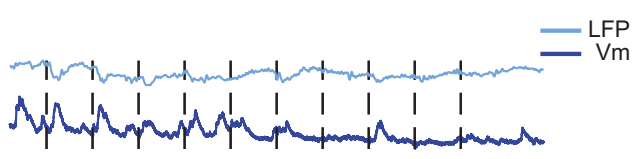

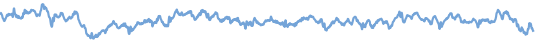
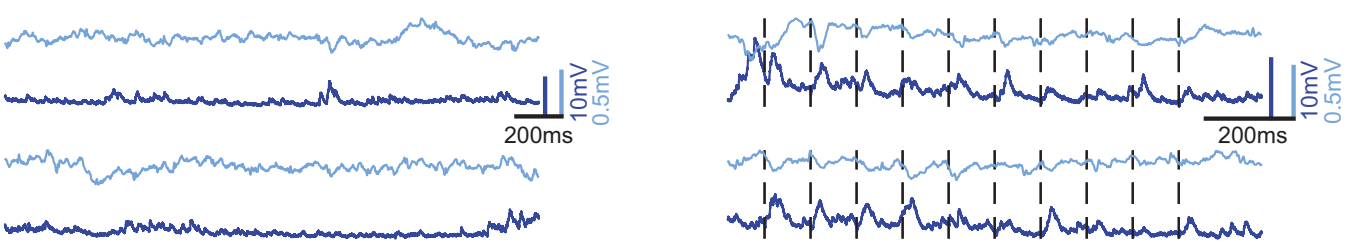

E

$F$

Noise-correction
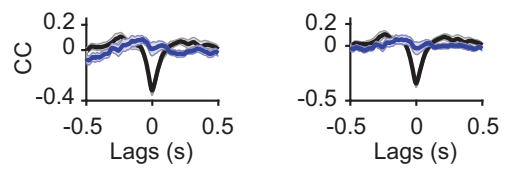

J

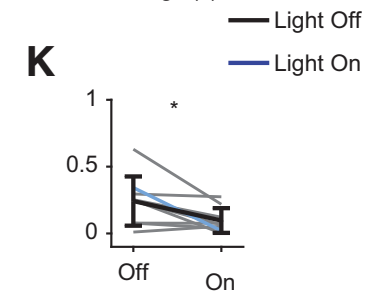

—Light Off

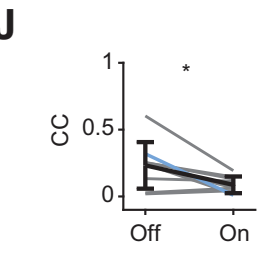

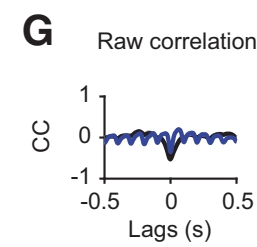

$\mathbf{L}$

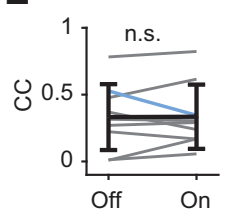

H

Noise-correlation I

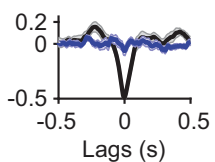

M

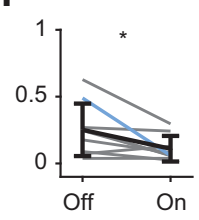

Signal-correlation

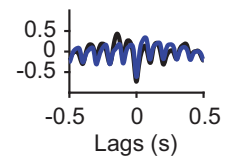

N

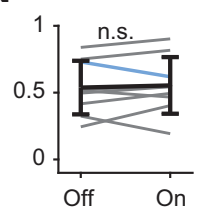

Figure 11. Optogenetic activation of cholinergic fibers decorrelates $V_{m}-L F P$ activities in the local cortical network. $A, B$, Examples of simultaneous recorded $V_{m}$ and nearby $L F P$ recordings during spontaneous activity in control conditions $(\boldsymbol{A})$ and during optogenetic stimulation $(\boldsymbol{B})$. $\boldsymbol{C}, \boldsymbol{D}$, same as $\boldsymbol{A}$ and $\boldsymbol{B}$ but for sensory-evoked responses. Dashed lines mark whisker deflections onset. $\boldsymbol{E}$, Spontaneous raw cross-correlations, presented as mean \pm SEM. $\boldsymbol{F}$, Same as $\boldsymbol{E}$ but for the noise correlations. $\boldsymbol{G}, \boldsymbol{H}$, Same as $\boldsymbol{E}$ and $\boldsymbol{F}$ but for sensory-evoked responses. $\boldsymbol{I}$, Signal correlations. $\boldsymbol{E}-\boldsymbol{I}$ were calculated from the same recording of $L F P-V_{m}$ shown in $\boldsymbol{A}-\boldsymbol{D}$. J, Spontaneous zero-lag (Pearson) raw correlations for the population of $V_{\mathrm{m}}-\mathrm{LFP}$ recordings. $\boldsymbol{K}$, Spontaneous zero-lag (Pearson) noise correlations for the population of $V_{\mathrm{m}}$-LFP recordings. $L, \boldsymbol{M}$, Same as $\boldsymbol{J}$ and $\boldsymbol{K}$ but for sensory evoked responses. $\boldsymbol{N}$, Zero-lag (Pearson) of signal correlations for the population of $V_{\mathrm{m}}-\mathrm{LFP}$ recordings. Gray lines mark single neurons (example cell is in color), black lines mark population average. ${ }^{*} p<0.05$, n.s., non significant. Wilcoxon's signed-rank test, $n=9$ cells.

recurrent connections (Li et al., 2013; Lien and Scanziani, 2013; Cohen-Kashi Malina et al., 2016) such that the sensory response is in fact composed of both thalamic and cortical components. Therefore, we would expect that suppression of the intracortical synapse due to cholinergic inputs would decrease the cortical component of the response and lead to an overall decreased response amplitude, but this was not the case. There might be a few explanations. Facilitation of the thalamocortical synaptic release balances the muscarinic-induced suppression of the sensory response or it might imply the existence of parallel intracortical circuits for ongoing activity and sensory-evoked responses, where the recurrent connections that give rise to the cortical component of the sensory response are spared while the connections that create the spontaneous fluctuations are suppressed by ACh.

The finding that NB stimulation drastically reduces noise amplitude but does not affect the signal amplitude, together with no change in response amplitude, highlight the cholinergic-induced noise reduction rather than signal enhancement.

\section{Trial-to-trial variability and noise correlations}

The reliability of information encoding is affected by the trial-totrial response variability of neuronal signals (Zohary et al., 1994; 
Pillow et al., 2008). Variability of sensory-evoked cortical responses can be either private to a cell or shared among neurons. Private variability, for example, due to internal processes in the cell such as spike generation or external factors such as independent synaptic noise of unitary inputs (Deweese and Zador, 2004), can be averaged out if the population activity, rather than single neuron activity, is considered. Shared variability will lead to highly correlated trial-to-trial variability between neurons, that is, noise correlations, which will not average out and therefore might be detrimental for sensory coding depending on the specific structure of correlations in the network (Averbeck et al., 2006; Moreno-Bote et al., 2014).

There is an ongoing debate regarding the source of shared variability in cortical networks. A large body of research supports the idea of a cortical origin for the cortical noise correlations (Timofeev et al., 2000; Khatri et al., 2009; Schölvinck et al., 2015), in contrast to cortical variability inherited from shared thalamic inputs (Bruno and Sakmann, 2006; Sadagopan and Ferster, 2012). A recent study has provided direct evidence that, in contrast to the common assumption, the shared variability in the spontaneous activity and sensory responses in barrel cortex layer 4 is not a result of fluctuating correlated thalamic inputs; rather, the intracortical inputs are highly correlated whereas the thalamic inputs are weakly correlated (Cohen-Kashi Malina et al., 2016). Furthermore, noise correlations are modulated by the behavioral state of the animal (Cohen and Maunsell, 2009) and by sensory stimuli (Tan et al., 2014).

Our present data revealed that local activation of cholinergic inputs in the cortex significantly reduced both the $V_{\mathrm{m}}$ trial-totrial variability and $V_{\mathrm{m}}$-LFP noise correlations, suggesting that this variability was a shared variability introduced into the local network by correlated synaptic inputs. These findings further support a cortical origin of noise correlations. Moreover, they indicate that NB is capable of an active suppression of cortical noise correlations by acting directly on the cortex.

\section{References}

Ankri N, Legendre P, Faber DS, Korn H (1994) Automatic detection of spontaneous synaptic responses in central neurons. J Neurosci Methods 52:87-100. CrossRef Medline

Averbeck BB, Latham PE, Pouget A (2006) Neural correlations, population coding and computation. Nat Rev Neurosci 7:358-366. CrossRef Medline

Beierlein M, Gibson JR, Connors BW (2003) Two dynamically distinct inhibitory networks in layer 4 of the neocortex. J Neurophysiol 90:29873000. CrossRef Medline

Beltramo R, D'Urso G, Dal Maschio M, Farisello P, Bovetti S, Clovis Y, Lassi G, Tucci V, De Pietri Tonelli D, Fellin T (2013) Layer-specific excitatory circuits differentially control recurrent network dynamics in the neocortex. Nat Neurosci 16:227-234. CrossRef Medline

Briggs F, Mangun GR, Usrey WM (2013) Attention enhances synaptic efficacy and the signal-to-noise ratio in neural circuits. Nature 499:476-480. CrossRef Medline

Brombas A, Fletcher LN, Williams SR (2014) Activity-dependent modulation of layer 1 inhibitory neocortical circuits by acetylcholine. J Neurosci 34:1932-1941. CrossRef Medline

Bruno RM, Sakmann B (2006) Cortex is driven by weak but synchronously active thalamocortical synapses. Science 312:1622-1627. CrossRef Medline

Castro-Alamancos MA (2004) Absence of rapid sensory adaptation in neocortex during information processing states. Neuron 41:455-464. CrossRef Medline

Castro-Alamancos MA, Gulati T (2014) Neuromodulators produce distinct activated states in neocortex. J Neurosci 34:12353-12367. CrossRef Medline

Chen N, Sugihara H, Sur M (2015) An acetylcholine-activated microcircuit drives temporal dynamics of cortical activity. Nat Neurosci 18:892-902. CrossRef Medline
Chubykin AA, Roach EB, Bear MF, Shuler MG (2013) A cholinergic mechanism for reward timing within primary visual cortex. Neuron 77:723735. CrossRef Medline

Cohen MR, Maunsell JH (2009) Attention improves performance primarily by reducing interneuronal correlations. Nat Neurosci 12:1594-1600. CrossRef Medline

Cohen-Kashi Malina K, Mohar B, Rappaport AN, Lampl I (2016) Local and thalamic origins of correlated ongoing and sensory-evoked cortical activities. Nat Commun 7:12740. CrossRef Medline

Dasgupta R, Seibt F, Beierlein M (2018) Synaptic release of acetylcholine rapidly suppresses cortical activity by recruiting muscarinic receptors in layer 4. J Neurosci 38:5338-5350. CrossRef Medline

Destexhe A, Rudolph M, Paré D (2003) The high-conductance state of neocortical neurons in vivo. Nat Rev Neurosci 4:739-751. CrossRef Medline

Deweese MR, Zador AM (2004) Shared and private variability in the auditory cortex. J Neurophysiol 92:1840-1855. CrossRef Medline

Disney AA, Aoki C, Hawken MJ (2007) Gain modulation by nicotine in macaque V1. Neuron 56:701-713. CrossRef Medline

Disney AA, Aoki C, Hawken MJ (2012) Cholinergic suppression of visual responses in primate V1 is mediated by GABAergic inhibition. J Neurophysiol 108:1907-1923. CrossRef Medline

Donoghue JP, Carroll KL (1987) Cholinergic modulation of sensory responses in rat primary somatic sensory cortex. Brain Res 408:367-371. CrossRef Medline

Do JP, Xu M, Lee SH, Chang WC, Zhang S, Chung S, Yung TJ, Fan JL, Miyamichi K, Luo L, Dan Y (2016) Cell type-specific long-range connections of basal forebrain circuit. ELife 5:e13214. CrossRef Medline

Eggermann E, Feldmeyer D (2009) Cholinergic filtering in the recurrent excitatory microcircuit of cortical layer 4. Proc Natl Acad Sci U S A 106: 11753-11758. CrossRef Medline

Eggermann E, Kremer Y, Crochet S, Petersen CCH (2014) Cholinergic signals in mouse barrel cortex during active whisker sensing. Cell Rep 9:1654-1660. CrossRef Medline

Froemke RC, Carcea I, Barker AJ, Yuan K, Seybold BA, Martins AR, Zaika N, Bernstein H, Wachs M, Levis PA, Polley DB, Merzenich MM, Schreiner CE (2013) Long-term modification of cortical synapses improves sensory perception. Nat Neurosci 16:79-88. CrossRef Medline

Gabernet L, Jadhav SP, Feldman DE, Carandini M, Scanziani M (2005) Somatosensory integration controlled by dynamic thalamocortical feedforward inhibition. Neuron 48:315-327. CrossRef Medline

Gil Z, Connors BW, Amitai Y (1997) Differential regulation of neocortical synapses by neuromodulators and activity. Neuron 19:679-686. CrossRef Medline

Goard M, Dan Y (2009) Basal forebrain activation enhances cortical coding of natural scenes. Nat Neurosci 12:1444-1449. CrossRef Medline

Gritti I, Mainville L, Mancia M, Jones BE (1997) GABAergic and other noncholinergic basal forebrain neurons, together with cholinergic neurons, project to the mesocortex and isocortex in the rat. J Comp Neurol 383: 163-177. CrossRef Medline

Gritton HJ, Howe WM, Mallory CS, Hetrick VL, Berke JD, Sarter M (2016) Cortical cholinergic signaling controls the detection of cues. Proc Natl Acad Sci U S A 113:E1089-E1097. CrossRef Medline

Heiss JE, Katz Y, Ganmor E, Lampl I (2008) Shift in the balance between excitation and inhibition during sensory adaptation of S1 neurons. J Neurosci 28:13320-13330. CrossRef Medline

Henny P, Jones BE (2008) Projections from basal forebrain to prefrontal cortex comprise cholinergic, GABAergic and glutamatergic inputs to pyramidal cells or interneurons. Eur J Neurosci 27:654-670. CrossRef Medline

Herrero JL, Roberts MJ, Delicato LS, Gieselmann MA, Dayan P, Thiele A (2008) Acetylcholine contributes through muscarinic receptors to attentional modulation in V1. Nature 454:1110-1114. CrossRef Medline

Hirata A, Castro-Alamancos MA (2010) Neocortex network activation and deactivation states controlled by the thalamus. J Neurophysiol 103:11471157. CrossRef Medline

Hirata A, Castro-Alamancos MA (2011) Effects of cortical activation on sensory responses in barrel cortex. J Neurophysiol 105:1495-1505. CrossRef Medline

Hsieh CY, Cruikshank SJ, Metherate R (2000) Differential modulation of auditory thalamocortical and intracortical synaptic transmission by cholinergic agonist. Brain Res 880:51-64. CrossRef Medline

Kalmbach A, Waters J (2014) Modulation of high- and low-frequency com- 
ponents of the cortical local field potential via nicotinic and muscarinic acetylcholine receptors in anesthetized mice. J Neurophysiol 111:258272. CrossRef Medline

Kalmbach A, Hedrick T, Waters J (2012) Selective optogenetic stimulation of cholinergic axons in neocortex. J Neurophysiol 107:2008-2019. CrossRef Medline

Katz Y, Yizhar O, Staiger J, Lampl I (2013) Optopatcher-an electrode holder for simultaneous intracellular patch-clamp recording and optical manipulation. J Neurosci Methods 214:113-117. CrossRef Medline

Khatri V, Bruno RM, Simons DJ (2009) Stimulus-specific and stimulusnonspecific firing synchrony and its modulation by sensory adaptation in the whisker-to-barrel pathway. J Neurophysiol 101:2328-2338. CrossRef Medline

Kilgard MP, Merzenich MM (1998) Cortical map reorganization enabled by nucleus basalis activity. Science 279:1714-1718. CrossRef Medline

Kolisnyk B, Guzman MS, Raulic S, Fan J, Magalhães AC, Feng G, Gros R, Prado VF, Prado MAM (2013) ChAT-ChR2-EYFP mice have enhanced motor endurance but show deficits in attention and several additional cognitive domains. J Neurosci 33:10427-10438. CrossRef Medline

Kudoh SN, Taguchi T (2002) A simple exploratory algorithm for the accurate and fast detection of spontaneous synaptic events. Biosens Bioelectron 17:773-782. CrossRef Medline

Li L, Li YT, Zhou M, Tao HW, Zhang LI (2013) Intracortical multiplication of thalamocortical signals in mouse auditory cortex. Nat Neurosci 16: 1179-1181. CrossRef Medline

Lien AD, Scanziani M (2013) Tuned thalamic excitation is amplified by visual cortical circuits. Nat Neurosci 16:1315-1323. CrossRef Medline

Ljubojevic V, Luu P, De Rosa E (2014) Cholinergic contributions to supramodal attentional processes in rats. J Neurosci 34:2264-2275. CrossRef Medline

Madisen L, Mao T, Koch H, Zhuo JM, Berenyi A, Fujisawa S, Hsu YW, Garcia AJ, Gu X, Zanella S, Kidney J, Gu H, Mao Y, Hooks BM, Boyden ES, Buzsáki G, Ramirez JM, Jones AR, Svoboda K, Han X, et al. (2012) A toolbox of cre-dependent optogenetic transgenic mice for light-induced activation and silencing. Nat Neurosci 15:793-802. CrossRef Medline

McGinley MJ, David SV, McCormick DA (2015) Cortical membrane potential signature of optimal states for sensory signal detection. Neuron 87:179-192. CrossRef Medline

Metherate R, Ashe JH (1993) Ionic flux contributions to neocortical slow waves and nucleus basalis-mediated activation: whole-cell recordings in vivo. J Neurosci 13:5312-5323. CrossRef Medline

Metherate R, Cox CL, Ashe JH (1992) Cellular bases of neocortical activation: modulation of neural oscillations by the nucleus basalis and endogenous acetylcholine. J Neurosci 12:4701-4711. CrossRef Medline

Minces V, Pinto L, Dan Y, Chiba AA (2017) Cholinergic shaping of neural correlations. Proc Natl Acad Sci U S A 114:5725-5730. CrossRef Medline

Mitchell JF, Sundberg KA, Reynolds JH (2007) Differential attentiondependent response modulation across cell classes in macaque visual area V4. Neuron 55:131-141. CrossRef Medline

Moreno-Bote R, Beck J, Kanitscheider I, Pitkow X, Latham P, Pouget A (2014) Information-limiting correlations. Nat Neurosci 17:1410-1417. CrossRef Medline

Muñoz W, Tremblay R, Levenstein D, Rudy B (2017) Layer-specific modulation of neocortical dendritic inhibition during active wakefulness. Science 355:954-959. CrossRef Medline

Okun M, Lampl I (2008) Instantaneous correlation of excitation and inhibition during ongoing and sensory-evoked activities. Nat Neurosci 11: 535-537. CrossRef Medline

Oldford E, Castro-Alamancos MA (2003) Input-specific effects of acetylcholine on sensory and intracortical evoked responses in the "barrel cortex" in vivo. Neuroscience 117:769-778. CrossRef Medline

Pabst M, Braganza O, Dannenberg H, Hu W, Pothmann L, Rosen J, Mody I, van Loo K, Deisseroth K, Becker AJ, Schoch S, Beck H (2016) Astrocyte intermediaries of septal cholinergic modulation in the hippocampus. Neuron 90:853-865. CrossRef Medline

Parikh V, Kozak R, Martinez V, Sarter M (2007) Prefrontal acetylcholine release controls cue detection on multiple timescales. Neuron 56:141154. CrossRef Medline

Pillow JW, Shlens J, Paninski L, Sher A, Litke AM, Chichilnisky EJ, Simoncelli EP (2008) Spatio-temporal correlations and visual signalling in a complete neuronal population. Nature 454:995-999. CrossRef Medline

Pinto L, Goard MJ, Estandian D, Xu M, Kwan AC, Lee SH, Harrison TC, Feng G, Dan Y (2013) Fast modulation of visual perception by basal forebrain cholinergic neurons. Nat Neurosci 16:1857-1863. CrossRef Medline

Polack PO, Friedman J, Golshani P (2013) Cellular mechanisms of brain state-dependent gain modulation in visual cortex. Nat Neurosci 16:13311339. CrossRef Medline

Reimer J, Froudarakis E, Cadwell CR, Yatsenko D, Denfield GH, Tolias AS (2014) Pupil fluctuations track fast switching of cortical states during quiet wakefulness. Neuron 84:355-362. CrossRef Medline

Reimer J, McGinley MJ, Liu Y, Rodenkirch C, Wang Q, McCormick DA, Tolias AS (2016) Pupil fluctuations track rapid changes in adrenergic and cholinergic activity in cortex. Nat Commun 7:13289. CrossRef Medline

Renart A, de la Rocha J, Bartho P, Hollender L, Parga N, Reyes A, Harris KD (2010) The asynchronous state in cortical circuits. Science 327:587-590. CrossRef Medline

Risbrough V, Bontempi B, Menzaghi F (2002) Selective immunolesioning of the basal forebrain cholinergic neurons in rats: effect on attention using the 5-choice serial reaction time task. Psychopharmacology (Berl.) 164: 71-81. CrossRef Medline

Sadagopan S, Ferster D (2012) Feedforward origins of response variability underlying contrast invariant orientation tuning in cat visual cortex. Neuron 74:911-923. CrossRef Medline

Sakata S, Harris KD (2009) Laminar structure of spontaneous and sensoryevoked population activity in auditory cortex. Neuron 64:404-418. CrossRef Medline

Saunders A, Granger AJ, Sabatini BL (2015) Corelease of acetylcholine and GABA from cholinergic forebrain neurons. Elife 4. CrossRef Medline

Schölvinck ML, Saleem AB, Benucci A, Harris KD, Carandini M (2015) Cortical state determines global variability and correlations in visual cortex. J Neurosci 35:170-178. CrossRef Medline

Sillito AM, Kemp JA (1983) Cholinergic modulation of the functional organization of the cat visual cortex. Brain Res 289:143-155. CrossRef Medline

Smith SW (1997) The scientist and engineer's guide to digital signal processing. San Diego, CA:California Technical Publishing.

Soma S, Shimegi S, Suematsu N, Tamura H, Sato H (2013) Modulationspecific and laminar-dependent effects of acetylcholine on visual responses in the rat primary visual cortex. PloS One 8:e68430. CrossRef Medline

Tan AY, Chen Y, Scholl B, Seidemann E, Priebe NJ (2014) Sensory stimulation shifts visual cortex from synchronous to asynchronous states. Nature 509:226-229. CrossRef Medline

Timofeev I, Grenier F, Bazhenov M, Sejnowski TJ, Steriade M (2000) Origin of slow cortical oscillations in deafferented cortical slabs. Cereb. Cortex 10:1185-1199. CrossRef Medline

Urban-Ciecko J, Jouhanneau JS, Myal SE, Poulet JFA, Barth AL (2018) Precisely timed nicotinic activation drives sst inhibition in neocortical circuits. Neuron 97:611-625.e5. CrossRef Medline

Vinck M, Batista-Brito R, Knoblich U, Cardin JA (2015) Arousal and locomotion make distinct contributions to cortical activity patterns and visual encoding. Neuron 86:740-754. CrossRef Medline

von Engelhardt J, Eliava M, Meyer AH, Rozov A, Monyer H (2007) Functional characterization of intrinsic cholinergic interneurons in the cortex. J Neurosci 27:5633-5642. CrossRef Medline

Xu M, Chung S, Zhang S, Zhong P, Ma C, Chang WC, Weissbourd B, Sakai N, Luo L, Nishino S, Dan Y (2015) Basal forebrain circuit for sleep-wake control. Nat Neurosci 18:1641-1647. CrossRef Medline

Zohary E, Shadlen MN, Newsome WT (1994) Correlated neuronal discharge rate and its implications for psychophysical performance. Nature 370:140-143. CrossRef Medline 